\title{
TRANSFORMACIÓN Y RESIGNIFICACIÓN DE LA PARAFERNALIA ALUCINÓGENA PREHISPÁNICA EN ATACAMA A LA LUZ DE UN DOCUMENTO DEL SIGLO XVII
}

\author{
Helena Horta Tricallotis', Jorge Hidalgo Lehuedé ${ }^{2}$ y Valentina Figueroa Larre
}

\begin{abstract}
Resumen
Un documento fechado en 1674 y referido a una campaña de extirpación de ídolos llevada a cabo en Atacama (Lasana, Caspana y Ayquina), parece dar cuenta de la sobrevivencia en contexto colonial de ciertos instrumentos del culto religioso prehispánico, específicamente de tabletas para inhalar alucinógenos que fueron utilizadas en rituales chamánicos. La descripción que se hace en el documento sobre tales objetos es suficientemente clara como para establecer correlatos -al menos en un caso- con un estilo de la parafernalia propia del período Intermedio Tardío y del Horizonte incaico en el área atacameña, el cual se centra en la representación de la cabeza de un felino. Aquí este estilo es definido por primera vez en sus aspectos formales e iconográficos. Paralelamente, proponemos que a través de la información registrada en el documento referido, parece ser posible detectar un inédito fenómeno de transformación y resignificación de objetos del antiguo culto prehispánico en el nuevo escenario colonial: esto habría ocurrido por medio de una significativa modificación realizada en la función original de las tabletas mencionadas, así como en un nuevo sentido otorgado al culto mismo.
\end{abstract}

Palabras claves: tableta para alucinógenos; religión prehispánica; desierto de Atacama; extirpación de idolatrías; río Loa

Abstract

A document dated to 1674 referred to a campaign of extirpation of idols held in Atacama (Lasana, Caspana and Ayquina) appears to account for the colonial survival of certain instruments of prehispanic religious worship, specifically snuff trays for inhaling hallucinogens that were used in shamanic rituals. The description given in the document on such objects is clear enough to establish correlates -at least in one case, a paraphernalia style from the Late Intermediate Period and Inca Horizon in Atacamenian area, which focuses on the representation of the head of a feline. In this paper, formal and iconographic aspects of this style are discussed for the first time. Additionally, we propose that through the information recorded in this document, it seems possible to detect an unprecedented phenomenon of transformation and redefinition of objects of ancient prehispanic worship in the new colonial scenario: this would have happened through a significant modification of the original function of the snuff trays in question, giving a new sense of the cult itself.

Key words: snuff tray; Prehispanic religion; Atacama Desert; extirpation of idolatry; Loa River

Recibido: Noviembre 2015. Aceptado: Abril 2016

\section{$*$ Introducción}

Un documento descubierto en forma independiente por uno de los autores de este artículo y el colega J. L. Martínez en la búsqueda de fuentes en el Archivo General de Indias, Sevilla, y luego por el colega Lautaro Núñez, constituye el primer registro documental conocido para el área atacameña acerca de cultos nativos realizados con elementos del complejo alucinógeno prehispánico, vigentes y resemantizados en el período colonial temprano. En el documento se describen tres ceremonias "idolátricas" descubiertas por el bachiller Domingo Suero Leiton de Rivera, cura de Atacama la Baja en aquel entonces; entre tales ritos, se describen dos que parecen involucrar a tabletas para inhalar alucinógenos, artefactos -que junto con el tubo inhalador- fueron en tiempos prehispánicos elementos clave de la práctica alucinatoria del Área centro-sur andina.

En base a este supuesto, hemos intentado identificar en la parafernalia arqueológica proveniente del río Loa, el salar de Atacama, costa de Antofagasta y la puna jujeña, qué tipo de tableta podría corresponder a lo descrito por el documento, para lo cual hemos analizado un vasto cor-

1 Instituto de Arqueología y Antropología-San Pedro de Atacama (IAA), Universidad Católica del Norte, Chile. hhorta@ucn.cl

2 Universidad de Chile, Departamento de Ciencias Históricas, Facultad de Filosofía y Humanidades, Santiago. Proyecto Fondecyt No 1130667 "Historia de los pueblos andinos de Arica, Tarapacá y Atacama: Dinámicas Imperiales, agencias indígenas y redes andinas de sociabilidad colonial".

3 Instituto de Arqueología y Antropología-San Pedro de Atacama (IAA), Universidad Católica del Norte, Chile.vfigueroa@ucn.cl 
pus de tales artefactos ${ }^{4}$, con el fin de encontrar algo semejante, y de esta manera apoyar nuestra hipótesis acerca la continuidad religiosa vivida por la población de la Atacama colonial, a través de un proceso de transformación y de una consecuente resignificación del antiguo culto, adaptando su función y significado a las nuevas exigencias de los tiempos coloniales.

\section{* El documento}

En el contexto del proceso de extirpación de las idolatrías o de eliminación de los cultos religiosos autóctonos de las comunidades andinas en la Provincia de Atacama, en el siglo XVII, el Bachiller Domingo Suero Leiton de Rivera, cura de Atacama la Baja, con cabecera en el pueblo de Chiu Chiu, levantó testimonio de sus méritos evangelizadores realizados en los pueblos de Lasana, Caspana y Ayquina, en la esperanza de ser recompensado por la jerarquía eclesiástica con alguna designación en una plaza religiosa más relevante. Se trata, entonces, de una carrera eclesiástica que se robustece, en esta época, mediante estos juicios ${ }^{5}$. Se plantea lo anterior como una advertencia para hacer la crítica interna del documento. Convenía a los sacerdotes que sus descubrimientos se leyeran como una franca derrota del demonio, para demostrar las dificultades de su labor evangelizadora y en consecuencia se trasladaban ideas europeas presentadas como parte de supuestos cultos americanos (Ramos 1992; Hidalgo 2011). En este contexto es conveniente despejar si el lenguaje del documento representa una transferencia de costumbres o tradiciones europeas o si bien los términos descriptivos de los objetos, así como las intenciones de los participantes están relatados en la clave de la lucha contra el demonio. En este artículo nosotros seguiremos otra alternativa crítica que es contrastar que las descripciones de los objetos utilizados en las ceremonias religiosas o incluso las palabras indígenas se corresponden

4 Horta inició esta búsqueda tras leer el documento mencionado, y dio cuenta de un avance de investigación el año 2008, con la ponencia titulada "Evidencias arqueológicas y etnohistóricas de la práctica alucinógena en Atacama” en las XII Jornadas de Historia Andina organizadas por el Instituto de Historia y Ciencias Sociales de la Universidad de Valparaíso, Facultad de Humanidades, en la ciudad de Viña del Mar.

5 Para una visión alternativa de la carrera eclesiástica véase Marsilli 2014 . tanto con los descubrimientos arqueológicos como con los aportes lingüísticos, para determinar que en efecto estamos ante tradiciones andinas, aun cuando sufriendo la influencia de cambios históricos.

El documento en cuestión fue ubicado en el "AGI, Lima, 263, número 9/1677. Lima, Informaciones de oficio y parte Domingo Suero Leiton de Rivera, presbítero, cura vicario del pueblo de San Francisco de Chio Chio, provincia de Atacama la Baja, testimonio de 1677, certificado en 1668", 12 fs. La parte pertinente, con transcripción de Priscilla Cisterna, fue publicada en Hidalgo 2011; también existe una versión paleográfica de Carlos Ruiz en Núñez y Castro 2011.

Nos parece importante transcribir de la Información de Domingo Suero Leiton de Rivera, la parte relativa al "Testimonio de aver quitado ydolos" [Al Margen] y que está fechado el 27 de septiembre de 1774:

"En testimonio de verdad Martín Peres de Estrada notario de visita yo don Josseph de la Torre y Salassar escrivano del Rey nuestro Señor certifico doy fee y testimonio de verdad a los que el presente vieren como aviendo ydo a los pueblos de Lassana, Caspana y Aiquina jurisdision de la provinçia de Atacama La Vaja desde este pueblo de san Françisco de Chio Chio de dicha provincia en compañía del Bachiller Domingo Suero Leiton de Rivera cura y vicario de dicho pueblo puerto de Cubija y sus anejos Le vi sacar tres ydolos

el vno en el dicho pueblo de Lassana en forma de un platillo quadrado de madera de algarobo con dos figuras de ximios en cuio hueco le echavan comidas las primeras que los yndios de dicho pueblo cogian en sus sementeras a quien ofresian adorassion,

Y el otro en el pueblo de Caspana a manera de lagarto de la mesma madera con la voca avierta al qual le ofresian piedras de varios colores de pedernales y polvos de colores y davanle adorassion en Vn alto serro que mira al de Potossí

en el dicho pueblo del Ayquina // saco el tersero ydolo de en medio de un caudaloso rrio que estava colocado en Vna peña que estava en la mitad de el, y la bañavan las aguas por entrambos lados a este ydolo segun dixeron los casiques le rendían adorassion y culto llevando el prinsipal Governador en las manos Vna olla nueba y otras veses cargandola en las espaldas y llena de mais y ba la yndia mas ansiana con vn palito sutily delgado tocandole y en lle- 
gando que llegavan con esta seremonia al rrio quebravan la olla en la dicha peña y levantando el grito a voses desian Caiatunar, que en su lengua materna dissen lo que en nuestro ydioma Hispanico buena cosecha" (el énfasis es nuestro).

De acuerdo con este texto, tanto en Lasana como en Caspana (Atacama la Baja), el principal instrumento del rito era "un platillo cuadrado de madera de algarrobo": esta descripción nos lleva a pensar -por una parte- que se estaba utilizando una tableta de formato rectangular, semejante a las conocidas tanto para el universo de la parafernalia local del período Medio (estilo San Pedro sensu Horta 2014), como para la post-Tiawanaku (estilo Circumpuneño sensu Horta 2012); por otra parte, la mención "en cuyo hueco le echaban comidas" refuerza nuestra propuesta acerca de que efectivamente el "platillo cuadrado" no puede ser más que una tableta para inhalar alucinógenos, ya que éstas constan de una cavidad rodeada por un borde perimetral, en la que se depositaba el polvo de cebil. Siguiendo con la descripción, las dos supuestas tabletas se diferenciaban entre sí por la figura tallada en ellas; en el primer caso, se habla de "dos figuras de simios", en el segundo, de algo similar a un lagarto con la boca abierta.

En esta ocasión nos ocuparemos de éste último tipo de tableta, ya que consideramos que tiene un correlato arqueológico directo y bien representado en la muestra estudiada por nosotros, cosa que no ocurre de la misma forma con el primer tipo ${ }^{6}$. Por su parte, los colegas Núñez y Castro (2011) han hecho un planteamiento diferente sobre este mismo tema, investigando iconográficamente, aunque no en Atacama, la presencia del simio.

También hay que destacar otra diferencia, esta vez en orden a la naturaleza de lo ofrendado en ambas tabletas; en una, eran los primeros frutos de la cosecha, en la otra, polvos y piedras de diferentes colores, pero en conjunto, incluyendo el tercer rito realizado en una peña en mitad del río, es evidente que el contexto general de las tres ceremonias se da en el marco de rogativas por la fertilidad vegetal y mineral obtenida.

\section{Resemantización de la parafernalia alucinógena}

En un trabajo anterior habíamos avanzado en algunos comentarios relativos al significado de los cultos des- critos y los aportes del momento histórico en que esto ocurre:

"Lo interesante es que en este caso, a nuestro juicio, las tabletas dejaron de ser parte de un complejo alucinógeno para integrarse en una parafernalia distinta vinculada con un ritual de fertilidad de los campesinos de Lasana del siglo XVII. En el hueco de las tabletas depositaban los primeros granos que cogían de sus sementeras y los ofrecían en adoración. Si la tableta se había convertido en un ídolo, o en una representación de una divinidad a la que se ofrecía adoración o se agradecía por los frutos cosechados, estamos ante una resemantización colonial, donde un objeto antiguo y sagrado conectaba también con un pasado cuya memoria se desvanecía" (Hidalgo 2011: 134-135).

"La resemantización colonial de la tableta alucinógena, para un uso ritual distinto, es una indicación de cómo estaban cambiando los cultos, las memorias y la renovación de la religiosidad andina" (Hidalgo 2011: 136).

Del mismo modo avanzamos en confirmar el significado de la voz cunza caiatunar presente en el texto, que no figura como tal en ninguno de los glosarios de cunza conocidos, llegando a la conclusión que es una palabra enteramente cunza y vigente en los rituales del siglo XVII:

"La voz caiatunar que es traducida por buena cosecha tiene respaldo en el Glosario de la lengua Atacameña que reunió cerca de 1100 voces recopiladas por el presbitero Emilio Vaisse, Félix $2^{\circ}$ Hoyos y Aníbal Echeverría i Reyes publicada en 1896. Ckaya es traducida por bien y bueno (página 18); Ttunar a su vez por "terreno (Sepetunar: terreno de Peine donde siembran maíz azul.)"; "Ttupia: coronta"; "Ttuti: mazorca". El significado de buena cosecha que nos provee este documento, entonces, aporta con una nueva expresión en cunza y apunta a una acepción no incluida por los investigadores de fines del siglo XIX y es que Ttunar signifique también cosecha, aun que podría estar más directamente asociada a la idea de cosecha de maiz" (Hidalgo 2011: 137).

6 Anteriormente, uno de nosotros consideró la figura descrita de "simio" como una representación de un felino "mal interpretada por los extirpadores que confundieron la cola del felino estilizado con la de un mono" (Hidalgo 2011: 135, ver lámina en página 134).

7 Vaïsse et al. [1896] 2006:33. 


\section{Probanza de méritos de Francisco de Otal}

La información de otro documento es igualmente valiosa para iluminar las prácticas religiosas atacameñas del siglo XVII. Se trata de la probanza de méritos de Francisco de Otal fechada en 1645, casi treinta años antes de los acontecimientos registrados por el documento ya analizado del cura de Atacama. En un párrafo de dicha probanza que se refiere a una campaña de extirpación efectuada por Otal en Calama en 1635, se dice lo siguiente:

“... [Francisco de Otal] sacó todos los ídolos que por las acusaciones le dijeron los indios dónde estaban e juntando todo el pueblo nos hacía traer una carga de leña a cada uno y en particular en el de Calama que se juntó mucha leña y tomó el ídolo llamado Sotar Condi a quien todos los indios de estas provincias teníamos por dios, teniéndolo nuestro padre en la mano vestido de cumbi con su pillu y plumas en él de oro y pájaro flamenco..." (AGI Charcas legajo 92, f. 40r, año 1645, transcripción de Victoria Castro [2009], el énfasis es nuestro).

De acuerdo con esta información las comunidades de Atacama la Alta (San Pedro de Atacama) y Atacama la Baja (Chiu Chiu), o los "indios de estas provincias", rendían culto a una misma deidad de nombre Sotar Condi en 1635. Más allá del nombre mismo y de la particularidad del hecho de que haya estado vestido con textil cumbi incaico y un tocado específico, lo que nos interesa destacar, es precisamente el dato acerca de la existencia de una reli- gión compartida por las poblaciones atacameñas. Frente a la casi total carencia de información documental, este párrafo arroja luces insospechadas sobre el tema. En este sentido, si aceptamos como premisa el culto compartido a un dios, resultará también coherente constatar que los elementos que estaban siendo utilizados en el rito descubierto en Lasana, Caspana y Ayquina (Atacama la Baja), - tabletas de madera y rituales en sitios de agua corriente, similares a la limpia de canales, según nuestra propuesta - también eran conocidos en otros puntos de la cuenca del río Loa y del salar de Atacama, formando parte de una parafernalia compartida, tal como se desprende de la recopilación arqueológica resultante de esta investigación (Tabla 1).

\section{UN MILENIO DE PRÁCTICA ALUCINÓGENA EN ATACAMA}

Durante la prehistoria, San Pedro de Atacama (Región de Antofagasta, Chile) funcionó como un polo de atracción para diversas sociedades prehispánicas que aspiraban a intercambiar variados productos por los minerales de cobre del área atacameña, entre otros recursos locales. Las relaciones eran intensas y los productos intercambiados no se restringían a los cotidianos y domésticos, sino también incluían a los rituales y de alto valor simbólico, por integrar estos bienes al ámbito religioso.

De esta manera, durante el período Medio arriban a los

\begin{tabular}{|l|l|l|l|l|}
\hline Proveniencia & Descripción & Negistro, tumba & Pertenencia a museo y/o referencia bibliográfica ${ }^{2}$ & Adscripción temporal $^{\circ}$ \\
\hline Caspana, Loa & una cabeza & tableta S/N & ubicación actual desconocida; Le Paige 1958: foto 20 & Intermedio Tardío \\
\hline Caspana, Loa & dos cabezas & tableta S/N & ubicación actual desconocida; Le Paige 1958: foto 20 & Intermedio Tardío \\
\hline Caspana, Loa & una cabeza & tableta 23.076 & $\begin{array}{l}\text { tumba 39, cementerio Los Abuelos; MNHN, Santiago; } \\
\text { Torres 1987a: Plate 40 }\end{array}$ & Intermedio Tardío \\
\hline Caspana, Loa & dos cabezas & tableta S/N, tumba 23, C1 & Barón 1984: Lám. XXVI & Intermedio Tardío \\
\hline Lasana, Loa & dos cabezas & tableta 2207 & de Calama & Intermedio Tardío \\
\hline Lasana, Loa & una cabeza & tableta 15/9971 & Torres 1987a: Plate 68; MAI, Nueva York \\
\hline
\end{tabular}

1 El asterisco que acompaña a algunos ejemplares indica presencia de incrustaciones o la cavidad vacía que indica incrustaciones que se perdieron.

2 Con la excepción de las tabletas depositadas en museos estadounidenses y en los europeos de Madrid, Londres, Bruselas y Hamburgo, los ejemplares publicados en Ambrosetti (1908), Uhle (1913 y 1915), Latcham (1926 y 1938), Looser (1926), Le Paige (1958), Orellana (1963), Wassén (1967), Barón (1984) y los del Catálogo Angelo Campagner, todas las demás fueron estudiadas de primera mano, con análisis directo en los distintos museos que las conservan. 
TRANSFORMACIÓN Y RESIGNIFICACIÓN DE LA PARAFERNALIA ALUCINÓGENA PREHISPÁNICA EN ATACAMA A LA LUZ DE UN DOCUMENTO DEL SIGLO XVII

\begin{tabular}{|c|c|c|c|c|}
\hline Lasana, Loa & dos cabezas & tableta $27.29: 273$ & Museo de Hamburgo, Alemania & Intermedio Tardío? \\
\hline Toconce, Loa & dos cabezas & tableta 9096 , sin tumba & IIAM-San Pedro de Atacama & Intermedio Tardío \\
\hline Loa & una cabeza & tableta 1970 & Colección Rencoret, MNHN, Santiago & Intermedio Tardío \\
\hline Chiuchiu, Loa & una cabeza* & tableta 08865 & MA, Madrid & Intermedio Tardío? \\
\hline Chiuchiu, Loa & una cabeza* & tableta S/N $\mathrm{N}^{\circ}$ & MNA, Madrid http://ceres.mcu.es & Intermedio Tardío? \\
\hline Chiuchiu, Loa & una cabeza & tableta 41.0 .4798 & AMNH, Nueva York; Torres 1987a: Plate 45 & Intermedio Tardío? \\
\hline Chiuchiu, Loa & dos cabezas & tableta S/No & Uhle 1913: fig. 19 & Intermedio Tardío \\
\hline Chiuchiu, Loa & dos cabezas & tableta S/No & Uhle 1913: fig. 20 & Intermedio Tardío \\
\hline Chiuchiu, Loa & una cabeza & tableta S/No & Uhle 1913: fig. 21 & Intermedio Tardío \\
\hline Chiuchiu, Loa & una cabeza & tableta S/No & Uhle 1913: fig. 22 & Intermedio Tardío \\
\hline Chiuchiu, Loa & una cabeza & tableta S/No & Uhle 1913: fig. 23 & Intermedio Tardío \\
\hline Chiuchiu, Loa & una cabeza* & tableta 14090 & MHN, Santiago & Intermedio Tardío \\
\hline Chiuchiu, Loa & una cabeza & tableta $\mathrm{A}_{3} 12097-0$ & AMNH, Nueva York & Intermedio Tardío? \\
\hline Chunchurí, Loa & una cabeza* & tableta 1999.1 .172 & Durán et al. 200o: fig. 48; MNHN, Santiago & Intermedio Tardío \\
\hline Chunchurí, Loa & dos cabezas & tableta 1999.1 .187 & Durán et al. 200o: fig. 51; MNHN, Santiago & Intermedio Tardío \\
\hline Chunchurí, Loa & dos cabezas & tableta 1999.1 .188 & Durán et al. 2000: fig. 52; MNHN, Santiago & Intermedio Tardío \\
\hline Chunchurí, Loa & una cabeza & tableta 1999.1 .189 & Durán et al. 200o: fig. 49; MNHN, Santiago & Intermedio Tardío \\
\hline Chunchurí, Loa & una cabeza* & tableta 1999.1 .190 & Durán et al. 200o: fig. 42; MNHN, Santiago & Intermedio Tardío \\
\hline Chunchurí, Loa & una cabeza & tableta 1999.1 .191 & Durán et al. 2000: fig. 43; MNHN, Santiago & Intermedio Tardío \\
\hline Chunchurí, Loa & una cabeza & tableta 1999.1.192 & Durán et al. 2000: fig. 75; MNHN, Santiago & Intermedio Tardío \\
\hline Chunchurí, Loa & una cabeza & tableta A 2045 & Colección Aichel, Museo de Schleswig, Alemania & Intermedio Tardío \\
\hline Chunchurí, Loa & una cabeza & tableta A 2048 & Colección Aichel, Museo de Schleswig, Alemania & Intermedio Tardío \\
\hline Chunchurí, Loa & una cabeza* & tableta $5773 \mathrm{Cal} 287$ & MAP, Mónaco & Intermedio Tardío \\
\hline Chunchurí, Loa & una cabeza & tableta $5775 \mathrm{Cal} 289$ & MAP, Mónaco & Intermedio Tardío \\
\hline Chunchurí, Loa & una cabeza & tableta 627 & MHN, Santiago (Colección Uhle) & Intermedio Tardío \\
\hline La Paya, Salta & una cabeza & tableta 1129 & Ambrosetti 1908: fig. 88 & $\begin{array}{l}\text { Intermedio Tardío, } \\
\text { Tardío }\end{array}$ \\
\hline La Paya, Salta & una cabeza & tableta 4273 & Museo de La Plata, Argentina & $\begin{array}{l}\text { Intermedio Tardío, } \\
\text { Tardío }\end{array}$ \\
\hline La Paya, Salta & dos cabezas* & tableta 2134 & $\begin{array}{l}\text { Ambrosetti 1908: fig. 267; Museo Arqueológico Dr. } \\
\text { Eduardo Casanova, Tilcara }\end{array}$ & $\begin{array}{l}\text { Intermedio Tardío, } \\
\text { Tardío }\end{array}$ \\
\hline Calilegua, Jujuy & una cabeza & tableta $13 / 3651$ & Torres 1987a: Plate 145; MAI, Nueva York & Intermedio Tardío \\
\hline Casabindo, Jujuy & una cabeza* & tableta S/N ${ }^{\circ}$ & Krapovickas 1958-59: fig. 13; MEJBA & Intermedio Tardío \\
\hline Cusi Cusi, Jujuy & una cabeza* & tableta CCLM & $\begin{array}{l}\text { Museo Arqueológico Provincial de Jujuy; Ruiz y Albeck } \\
\text { 1999: Fig. 1. }\end{array}$ & Intermedio Tardío \\
\hline Doncellas, Jujuy & una cabeza & tableta $43-2354$ & MEJBA; Zerries 1968: 137 & $\begin{array}{l}\text { Período Medio e } \\
\text { Intermedio Tardío }\end{array}$ \\
\hline Tchecar & una cabeza + cola & tableta 9296, tumba 1194 & IIAM-San Pedro de Atacama; Tarragó 1989: 43.4 & $\begin{array}{l}\text { Período Medio e } \\
\text { Intermedio Tardío }\end{array}$ \\
\hline Tchecar & una cabeza + cola & tableta 9088 , tumba 1139 & IIAM-San Pedro de Atacama; Tarragó 1989: 43.5 & $\begin{array}{l}\text { Período Medio e } \\
\text { Intermedio Tardío }\end{array}$ \\
\hline Tchecar & una cabeza & tableta $\mathrm{S} / \mathrm{N}^{\circ}$, tumba 1131 & IIAM-San Pedro de Atacama; Tarragó 1989:43.6 & $\begin{array}{l}\text { Período Medio e } \\
\text { Intermedio Tardio }\end{array}$ \\
\hline Tchecar & una cabeza + cola & tableta 8836 , tumba 1136 & IIAM-San Pedro de Atacama & $\begin{array}{l}\text { Período Medio e } \\
\text { Intermedio Tardío }\end{array}$ \\
\hline
\end{tabular}


Helena Horta Tricallotis, Jorge Hidalgo lehuedé y Valentina Figueroa larre

\begin{tabular}{|c|c|c|c|c|}
\hline Tchecar & una cabeza & tableta 8976 , tumba 788 & IIAM-San Pedro de Atacama & $\begin{array}{l}\text { Período Medio e } \\
\text { Intermedio Tardío }\end{array}$ \\
\hline Tchecar & una cabeza* & tableta 8979 , tumba 792 & IIAM-San Pedro de Atacama & $\begin{array}{l}\text { Período Medio e } \\
\text { Intermedio Tardío }\end{array}$ \\
\hline Tchecar & una cabeza* & tableta 8986 , tumba 1116 & IIAM-San Pedro de Atacama; Tarragó 1989: 44.2 & $\begin{array}{l}\text { Período Medio e } \\
\text { Intermedio Tardío }\end{array}$ \\
\hline Catarpe-2 & una cabeza & tableta 9312, tumba 2317 & IIAM-San Pedro de Atacama; Tarragó 1989: 43.7 & $\begin{array}{l}\text { Intermedio Tardío, } \\
\text { Tardío }\end{array}$ \\
\hline Catarpe-2 & una cabeza* & tableta 9010 , tumba 2327 & IIAM-San Pedro de Atacama; Tarragó 1989: 43.8 & $\begin{array}{l}\text { Intermedio Tardío, } \\
\text { Tardío }\end{array}$ \\
\hline Catarpe-2 & una cabeza & tableta 8978 , tumba 1884 & IIAM-San Pedro de Atacama & $\begin{array}{l}\text { Intermedio Tardío, } \\
\text { Tardío }\end{array}$ \\
\hline Catarpe-2 & una cabeza & tableta 8995 , tumba 1816 & IIAM-San Pedro de Atacama & $\begin{array}{l}\text { Intermedio Tardío, } \\
\text { Tardío }\end{array}$ \\
\hline Catarpe-2 & una cabeza* & tableta $\mathrm{S} / \mathrm{N}^{\circ}$, tumba 1877 & IIAM-San Pedro de Atacama & $\begin{array}{l}\text { Intermedio Tardío, } \\
\text { Tardío }\end{array}$ \\
\hline Catarpe-2 & una cabeza & $\begin{array}{l}\text { tableta destruida, tumba } \\
2348\end{array}$ & IIAM-San Pedro de Atacama, Notas Le Paige & $\begin{array}{l}\text { Intermedio Tardío, } \\
\text { Tardío }\end{array}$ \\
\hline Catarpe-2 & dos cabezas & $\begin{array}{l}\text { tableta S/ } \mathrm{N}^{\circ} \text {, tumba } 2309 \\
(1809)\end{array}$ & IIAM-San Pedro de Atacama & $\begin{array}{l}\text { Intermedio Tardío, } \\
\text { Tardío }\end{array}$ \\
\hline Catarpe Acequia & dos cabezas & $\begin{array}{l}\text { tableta S/N } \mathrm{N}^{\circ} \text {, tumba } \\
2403-08\end{array}$ & IIAM-San Pedro de Atacama; Tarragó 1989: 48.4 & $\begin{array}{l}\text { Intermedio Tardío, } \\
\text { Tardío }\end{array}$ \\
\hline Catarpe & dos cabezas & tableta 354 & $\begin{array}{l}\text { Colección Angelo Campagner, Italia; Laurencich M. } \\
\text { y Colella (2008) }\end{array}$ & $\begin{array}{l}\text { Intermedio Tardío, } \\
\text { Tardío }\end{array}$ \\
\hline Catarpe ("pukara") & una cabeza & tableta 362 & $\begin{array}{l}\text { Colección Angelo Campagner, Italia; Laurencich M. } \\
\text { y Colella (2008) }\end{array}$ & $\begin{array}{l}\text { Intermedio Tardío, } \\
\text { Tardío }\end{array}$ \\
\hline Calar & una cabeza & tableta 8979 , tumba 792 & IIAM-San Pedro de Atacama & Intermedio Tardío \\
\hline Coyo Oriente & una cabeza & tableta 9025 , tumba 4180 & IIAM-San Pedro de Atacama & $\begin{array}{l}\text { Período Medio e } \\
\text { Intermedio Tardío }\end{array}$ \\
\hline Coyo Oriente & una cabeza & tableta 8991, tumba 3917 & IIAM-San Pedro de Atacama & $\begin{array}{l}\text { Período Medio e } \\
\text { Intermedio Tardío }\end{array}$ \\
\hline Solcor Plaza & una cabeza & tableta 8987, tumba 621 & IIAM-San Pedro de Atacama & $\begin{array}{l}\text { Período Medio e } \\
\text { Intermedio Tardío }\end{array}$ \\
\hline Yaye-1 & una cabeza + cola & tableta 8999 , tumba 3420 & IIAM-San Pedro de Atacama; Tarragó 1989: 43.11 & $\begin{array}{l}\text { Intermedio Tardío, } \\
\text { Tardío }\end{array}$ \\
\hline Yaye-1 & una cabeza ${ }^{*}+$ cola & tableta 9123 , tumba 1417 & IIAM-San Pedro de Atacama & $\begin{array}{l}\text { Intermedio Tardío, } \\
\text { Tardío }\end{array}$ \\
\hline Yaye-2 & una cabeza* & tableta 8980 , tumba 1560 & IIAM-San Pedro de Atacama; Tarragó 1989: 43.9 & $\begin{array}{l}\text { Intermedio Tardío, } \\
\text { Tardío }\end{array}$ \\
\hline Yaye-2 & una cabeza* + cola & tableta 8993 , tumba 1577 & IIAM-San Pedro de Atacama & $\begin{array}{l}\text { Intermedio Tardío, } \\
\text { Tardío }\end{array}$ \\
\hline Yaye-4 & una cabeza* & tableta 8982 , tumba 1518 & IIAM-San Pedro de Atacama, Tarragó 1989:43.10 & $\begin{array}{l}\text { Intermedio Tardío, } \\
\text { Tardío }\end{array}$ \\
\hline Quitor-o & una cabeza & tableta $\mathrm{S} / \mathrm{N}^{\circ}$ & ubicación actual desconocida; Orellana 1963, pág. 9 & Intermedio Tardío? \\
\hline Quitor-6 & una cabeza & tableta 9275, tumba 2702 & IIAM-San Pedro de Atacama & $\begin{array}{l}\text { Período Medio e } \\
\text { Intermedio Tardío }\end{array}$ \\
\hline Quitor-9 & una cabeza & $\begin{array}{l}\text { tableta ausente, tumba } \\
3236-3237\end{array}$ & $\begin{array}{l}\text { IIAM-San Pedro de Atacama; Notas Le Paige } \\
\text { 1955-75; Tarragó 1989: } 44\end{array}$ & $\begin{array}{l}\text { Período Medio e Inter- } \\
\text { medio Tardío, fechado } \\
\text { C14 no calibrado de } \\
\text { 1050 d.C. }\end{array}$ \\
\hline Solor-3? & una cabeza & tableta 8981 , momia $35 ?$ & IIAM-San Pedro de Atacama; Tarragó 1989: 43.2 & Intermedio Tardío? \\
\hline
\end{tabular}


TRANSFORMACIÓN Y RESIGNIFICACIÓN DE LA PARAFERNALIA ALUCINÓGENA

PREHISPÁNICA EN ATACAMA A LA LUZ DE UN DOCUMENTO DEL SIGLO XVII

\begin{tabular}{|c|c|c|c|c|}
\hline S.P. de Atacama & una cabeza & tableta $17 / 7551$ & Torres 1987a: Plate 110a, MAI, Nueva York & Intermedio Tardío? \\
\hline S.P. de Atacama & dos cabezas & tableta S/Nº, tumba 2309 & IIAM-San Pedro de Atacama & Intermedio Tardío? \\
\hline S.P. de Atacama & dos cabezas & tableta $\mathrm{S} / \mathrm{N}^{\circ}$ & Latcham 1938: Fig.2a & Intermedio Tardío? \\
\hline S.P. de Atacama & dos cabezas & tableta S/N $\mathrm{N}^{\circ}$ & Latcham 1938: Fig.2b & Intermedio Tardío? \\
\hline Atacama & una cabeza & tableta S/N ${ }^{\circ}$ & Museo Precolombino de Uruguay; Wassén 1967: Fig. 26 & Intermedio Tardío? \\
\hline Pisagua & dos cabezas* & tableta S/No & Uhle 1915: fig. 1/2 & Intermedio Tardío? \\
\hline $\begin{array}{l}\text { Caleta Huelén-12, } \\
\text { Loa }\end{array}$ & una cabeza & tableta 94.1 .865 , tumba 46 & MRA & Intermedio Tardío? \\
\hline Los Verdes, Iquique & una cabeza* & tableta S/No & MRI, Sanhueza 1985: fig. 2 a & Intermedio Tardío? \\
\hline Los Verdes, Iquique & una cabeza* & tableta S/No & MRI, Sanhueza 1985: fig. 2 b & Intermedio Tardío? \\
\hline Caldera & una cabeza & tableta $\mathrm{S} / \mathrm{N}^{\circ}$ & Latcham 1926: fig. 1-2 & Intermedio Tardío? \\
\hline Copiapó & una cabeza & tableta $\mathrm{S} / \mathrm{N}^{\circ}$ & Latcham 1926: fig. 3-4 & Intermedio Tardío? \\
\hline Playa Miller-2, Arica & una cabeza & tableta 3678 , tumba 283 & MASMA; Chacama 2001 & $\begin{array}{l}\text { Intermedio Tardío y } \\
\text { Tardío }\end{array}$ \\
\hline Playa Miller-4, Arica & dos cabezas & tableta 7083 , tumba 31 & MASMA & $\begin{array}{l}\text { Intermedio Tardío y } \\
\text { Tardío }\end{array}$ \\
\hline Sin procedencia & una cabeza & tableta 2593 & MCHAP & Intermedio Tardío? \\
\hline Sin procedencia & una cabeza* & tableta 2594 & MCHAP & Intermedio Tardío? \\
\hline Sin procedencia & una cabeza & tableta 1920 & MCHAP & Intermedio Tardío? \\
\hline Sin procedencia & dos cabezas & tableta 1886 & MCHAP & Intermedio Tardío? \\
\hline Sin procedencia & una cabeza & tableta 026 & MCHAP & Intermedio Tardío? \\
\hline Sin procedencia & dos cabezas & tableta 971 & MCHAP & Intermedio Tardío? \\
\hline Sin procedencia & una cabeza & tableta 1970 & Looser 1926: fig. 5 & Intermedio Tardío? \\
\hline Sin procedencia & una cabeza & tableta $1 \mathrm{~S} / \mathrm{N}^{\circ}$ & Colección particular P. Chadwick, Viña del Mar & Intermedio Tardío? \\
\hline Sin procedencia & una cabeza & tableta $2 \mathrm{~S} / \mathrm{N}^{\circ}$ & Colección particular P. Chadwick, Viña del Mar & Intermedio Tardío? \\
\hline Sin procedencia & dos cabezas & tableta 171785 & Field Museum, Chicago & Intermedio Tardío? \\
\hline Sin procedencia & una cabeza & tableta $\mathrm{S} / \mathrm{N}^{\circ}$ & Field Museum, Chicago & Intermedio Tardío? \\
\hline Sin procedencia & una cabeza* & tableta 031745 & Museo Etnográfico de Amberes, Bélgica & Intermedio Tardío? \\
\hline Norte de Chile & una cabeza & tableta 1950 AM 12 & British Museum & Intermedio Tardío? \\
\hline
\end{tabular}

Tabla 1. Relación de los ejemplares recabados de tabletas para inhalar alucinógenos talladas con cabeza de felino, con su proveniencia, descripción, pertenencia a museo y adscripción temporal. 
oasis de San Pedro tabletas y otros elementos de la parafernalia de diferentes procedencias, lo cual se refleja en la aparición de diversos estilos de talla para estos instrumentos de la práctica alucinatoria atacameña. Algunos de éstos han sido estudiados desde hace más de un siglo, mientras que otros estilos sólo han sido abordados y definidos en las últimas décadas (entre otros, Ambrosetti 1908; Uhle 1913, 1915; Looser 1926; Oyarzún 1931; Latcham 1938; Le Paige 1958, 1965; Núñez 1962, 1963; Wassén 1965, 1972; Barón 1984; Berenguer 1985, 1987 , 1998, 2001; Berenguer et al. 1980; Torres 1984a, 1984b, 1986, 1987a, 1987b, 1998, 2001a, 2001b, 2004; Torres y Conklin 1995; Thomas y Benavente 1984; Llagostera 1995, 1996, 2001, 2004, 2006a y b; Llagostera et al. 1988; Montenegro 2004a).

\section{Diferentes rostros para una práctica compartida}

Dentro de este marco general, uno de nosotros ha venido desarrollando en trabajos anteriores definiciones estilísticas e iconográficas que han redundado en la definición del: a) estilo San Pedro (señalado como de carácter microlocal y circunscrito al salar de Atacama, y al mismo tiempo contemporáneo con las influencias culturales de Tiawanaku), y b) del estilo Circumpuneño, de vigencia post-Tiahuanaco y de carácter macroregional (costa del Pacífico, cuenca del río Loa, salar de Atacama, noroeste de Argentina) (Horta 2012 y 2014). De esta manera, lo que sabemos actualmente es que el panorama estilístico se componía de influencias foráneas ejercidas sobre Atacama (desde el altiplano circun-Titicaca, el noroeste de Argentina, y también desde otros puntos no definidos aún), y de expresiones culturales o tradiciones locales, desenvolviéndose en conjunto a través de varios siglos (ca. 400-1500 d.C.). Todo ello se ve plasmado en los hermosos tallados en madera realizados en tabletas y tubos para inhalar, espátulas, cucharas y cucharillas dosificadoras, morteritos y pilones, elementos registrados en los ajuares funerarios de miles de tumbas del área atacameña y zonas vecinas (Mostny 1958; Le Paige 1955-75, 1965; Orellana 1963; Tarragó 1989; Ayala et al. 1999; Durán et al. 2000; Montenegro 2002, 2004a y b; Sprovieri 2008-09; entre otros).

Cada uno de los estilos referidos cuenta con su propio repertorio visual y narrativo específico, aunque comparten un núcleo duro de creencias y conceptos ideológicos que dicen relación con el especial vínculo que se da entre un antropomorfo de características sobrenaturales y/o de alto rango (El Sacrificador) y un felino (véase cuadro-resumen en Tabla 2). Este último es ampliamente representado en estos lenguajes visuales, aunque ello no ocurre en su naturaleza de cuadrúpedo con formas realistas; por el contrario, en la amplia mayoría de los casos, el felino surge como "enmascaramiento" del antropomorfo mencionado (en el estilo Circumpuneño, por ejemplo, su representación se reduce a máscaras felinizadas sobrepuestas al rostro del antropomorfo, lo cual ha sido vinculado a un rito chamánico específico), o en el estilo San Pedro, como parte del atuendo del antropomorfo denotándolo como su alter ego (Horta 2012, 2014). Son escasas las configuraciones naturalistas del felino, destacándose por su excepcionalidad algunas obras maestras de la talla foránea altiplánica Tiawanaku, tales como la figura del felino en la tableta 1112 de la tumba 6 del cementerio Solcor 3 (Figura 1).

\section{El estilo Atacameño}

En este contexto general, destaca la existencia de un tipo de tableta, de cuyo borde superior arranca una cabeza de felino en talla tridimensional (Figura 2). Tal como se puede observar en la foto, la cabeza no se orienta hacia el individuo que usa la tableta, lo cual constituye una innovación importante, ya que en todos los otros estilos lo habitual es que las figuras que se tallan en la parte superior de la tableta, enfrenten al individuo que sostiene en la palma dicho implemento. Igualmente, es notable

\begin{tabular}{|l|l|l|}
\hline \multicolumn{1}{|c|}{ Denominación } & \multicolumn{1}{c|}{ Área de dispersión } & \multicolumn{1}{c|}{ Adscripción temporal } \\
\hline Estilo San Pedro & Salar de Atacama & Período Medio \\
\hline Estilo Circumpuneño & $\begin{array}{l}\text { Circumpuna (sur de Bolivia, noroeste de Argentina, } \\
\text { salar de Atacama, cuenca río Loa, costa Antofagasta) }\end{array}$ & Intermedio Tardío \\
\hline Estilo Atacameño & $\begin{array}{l}\text { Cuenca del río Loa, puna de Jujuy en el noroeste } \\
\text { argentino, salar de Atacama, costa del Pacífico }\end{array}$ & IntermedioTardío, Tardío, ¿Colonial temprano? \\
\hline
\end{tabular}

Tabla 2. Estilos de parafernalia alucinógena definidos para la subárea Circumpuneña (sensu Horta 2012 y 2014) 


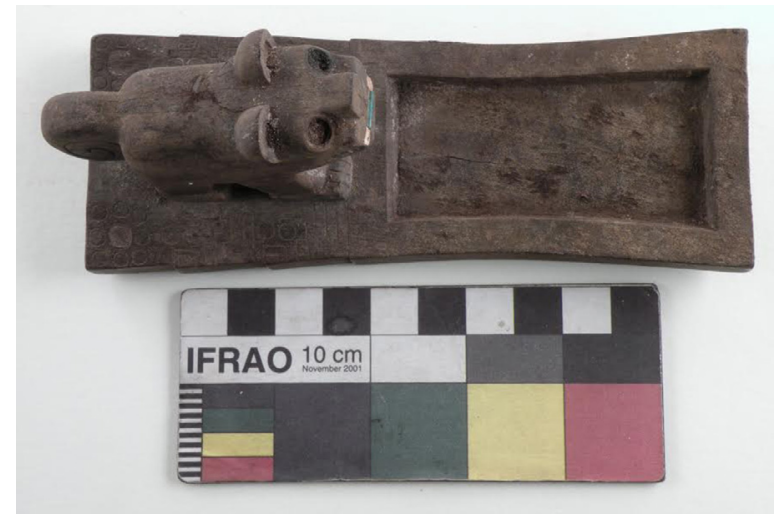

Figura 1. Tableta 1112 con felino naturalista y dentadura incrustada de piedras, estilo Tiawanaku. Cementerio Solcor 3, tumba 6 (registro fotográfico Col. IIAM 401).

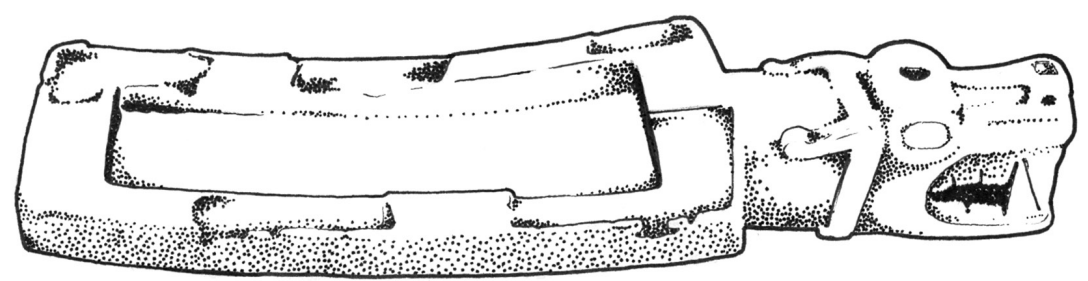

Figura 2. Tableta con cabeza naturalista de felino proveniente de Casabindo, Museo Etnográfico J. B. Ambrosetti, Buenos Aires (dibujo ideal de la pieza realizado en base a fotografía por Alex Olave).

la estandarización de estas cabezas en términos de formato, técnica e iconografía; en la muestra recabada (94 ejemplares, véase Tabla 1) ha sido posible observar dos variantes estilísticas: una naturalista y otra esquemática. En la primera variante, se observa al felino reducido a una cabeza (o en un número menor de casos, dos cabezas idénticas y paralelas) con un morro desarrollado, las fau- ces mostrando la dentadura (en ocasiones con colmillos entrecruzados en los vértices), ojos redondos sobresalientes, fosas nasales dilatadas y mandíbula recta (Figura 3, Figura 4a, b y c).

Esta forma de representación experimenta a través del tiempo una marcada tendencia hacia la estilización y

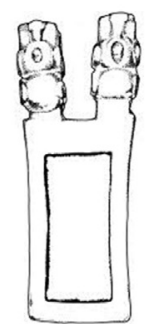

a

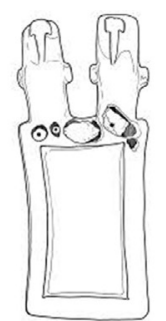

b

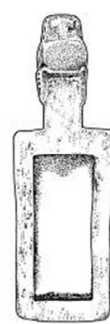

C

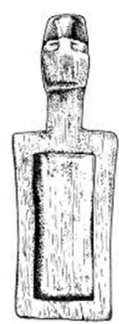

d

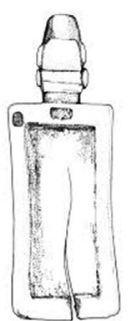

e

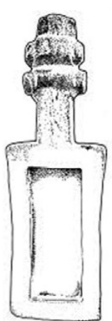

$f$

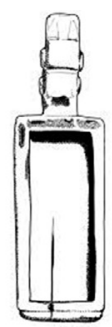

$\mathrm{g}$

Figura 3. Tabletas con cabeza naturalista de felino. Dibujo de piezas seleccionadas de la muestra realizado por Alex Olave. a) Tableta 971 del Museo Chileno de Arte Precolombino. b) tableta 9096 (Col. IIAM o17) de Toconce, sin referencia a tumba; c) Tableta 3678 de la tumba 283 del cementerio Playa Miller 2, MASMA; d) Tableta 43-2354 del Museo Etnográfico J. B. Ambrosetti, Buenos Aires; e) Tableta 5773 Cal. 287 proveniente de Chunchuri, río Loa. Museo de Antropología Prehistórica de Mónaco; f) Tableta 8981 (Col. IIAM 322) de proveniencia dudosa (iSolor 3?); g) Tableta S/N de La Matanza (Cusi Cusi), Museo Arqueológico Provincial de Jujuy, Argentina. 
simplificación de los detalles que denotaban al felino, derivando en una configuración más esquemática de la cabeza del felino (Figura 5), y en ciertos casos, en una estilización tan extrema, que impide reconocer al animal en una primera observación. En esta fase de la estilización sólo se destacan algunos de los rasgos que se enfatizan en la variante naturalista -tales como las fauces entreabiertas y los colmillos entrecruzados-, focalizándose el tallado básicamente en el morro y las protuberancias circulares de las orejas (Figuras 6 y 7). Se dan también casos aún más extremos, en los cuales sólo se talla una protuberancia a cada lado de la cabeza, indicando el lugar de las orejas sin ningún otro detalle (véase Figuras $5 \mathrm{c}$ y d). Este tipo de felinos esquematizados son los que han sido interpretados indistintamente por algunos autores, como "serpientes" (Durán et al. 2000: Fig. 43), motivo "abstracto" (Durán et al. 2000: Fig. 75), o como "cabeza de ofidio" (Montenegro 2004a: 63, 2b). Efectivamente, es difícil establecer la naturaleza de las cabezas de felino estilizadas cuando no son observadas en conjunto con las cabezas más naturalistas, ya que sólo con este ejercicio es posible apreciar la continuidad de rasgos que presentan unas y otras, y concluir por lo tanto, que las estilizadas corresponden a manifestaciones tardías de un mismo proceso de configuración visual, cuyo centro es el felino.

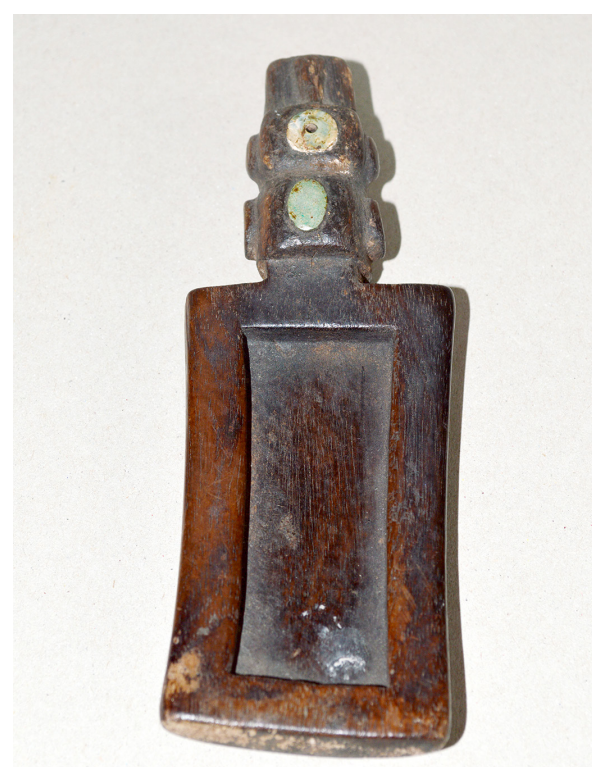

Figura 4a. Tableta con cabeza naturalista de felino, colección particular P. Chadwick, vista superior con el detalle

de piedras incrustadas (foto H. Horta).
Además, como característica especial de algunas de éstas (6 casos), es la aparición de una cola simbólica, la cual se reduce a una pequeña protuberancia, ubicada sobresaliendo del borde inferior de la tableta, en el lado opuesto a la cabeza (véanse Figura 5a-c y Figura 8).

Asimismo, hay que destacar que este tipo de ejemplar se ha encontrado exclusivamente en ofrendas de los cementerios Yaye y Tchecar (Tabla 3), ambos señalados como lugares de entierro de población de fines del período Medio, con continuidad en el Intermedio Tardío y el Tardío, en base a los artefactos depositados en los ajuares funerarios (Tarragó 1898; Le Paige 1958; Uribe 2002, Uribe et al. 2004, entre otros), y últimamente, en base a fechados del material osteológico: ca. 700-1200 d.C., perteneciendo a las fases Coyo y Solor (Hubbe et al. 2011).

En la variante esquemática, los cuellos se alargan, al punto de que en algunos casos se podría pensar en otro animal, eventualmente en un lagarto o serpiente: este punto es especialmente interesante, ya que nuestra propuesta es que precisamente una tableta de éste estilo, en su variante esquemática debió ser la empleada en el rito descubierto por el extirpador Rivera Leiton, mientras era realizado por miembros de la población loina en 1674 (Figuras 5a y 8$)$.

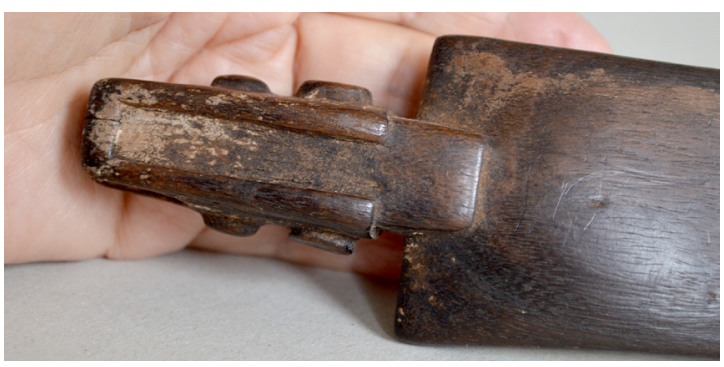

Figura 4b. Tableta con cabeza naturalista de felino, colección particular P. Chadwick, reverso de la pieza en la que se observa la línea de la mandíbula del animal (foto H. Horta).

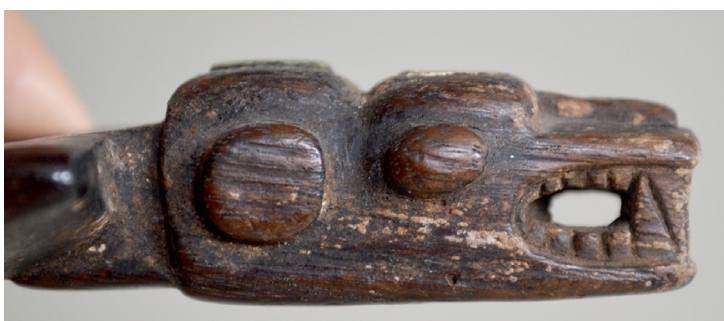

Figura 4c. Tableta con cabeza naturalista de felino, colección particular P. Chadwick, vista de perfil donde se observa el morro, los colmillos entrecruzados y las orejas del animal (foto H. Horta). 


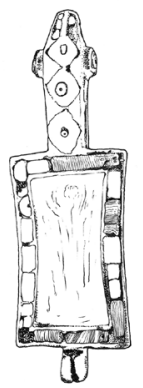

a

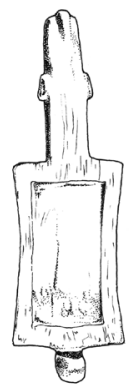

b

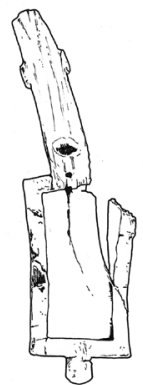

C

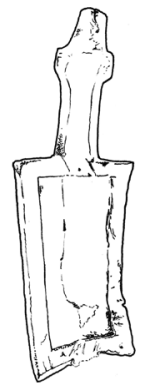

d

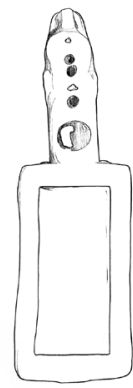

e

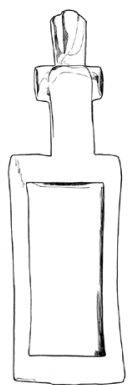

f

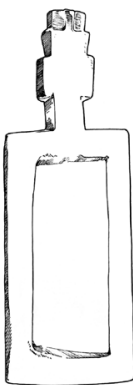

g

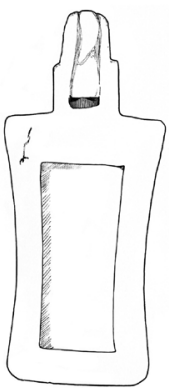

h

Figura 5. Tabletas con cabeza estilizada de felino. Dibujo de piezas seleccionadas de la muestra realizado por Alex Olave. a) Tableta 9123 (Col. IIAM 316), tumba 1417 del cementerio Yaye 1; b) Tableta 9088 (Col. IIAM 320) de la tumba 1139 del cementerio Tchecar; c) Tableta 8993 de la tumba 1577 del cementerio Yaye 2 (Col. IIAM 319); d) Tableta 8987 (Col. IIAM 120) de la tumba 621 del cementerio Solcor Plaza; e) Tableta S/N del cementerio Los Verdes, Museo Regional de Iquique; f) Tableta o046 del Museo Chileno de Arte Precolombino, sin procedencia; g) Tableta 9878 (Col. IIAM 310) de la tumba 1824 del cementerio Catarpe 2; h) Tableta 627 del cementerio de Chunchuri (Col. Uhle), Museo Histórico Nacional.

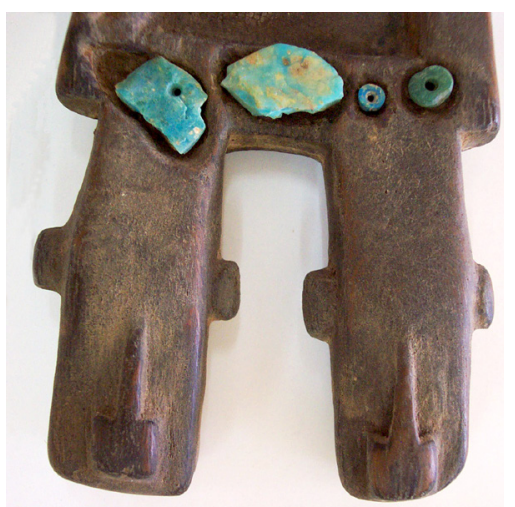

Figura 6. Detalle de la tableta 9096 (Col. IIAM o17) de Toconce, sin referencia a tumba; dos cabezas estilizadas de felino con incrustaciones en el borde superior (foto H. Horta).

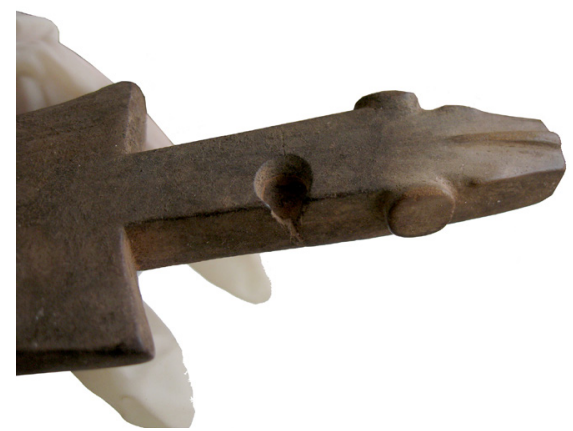

Figura 7a. Detalle de la tableta 9296 (Col. IIAM 317), tumba 1194 del cementerio Tchecar; se aprecia un orificio con huellas de quema en el cuello de la cabeza de felino (foto H. Horta).

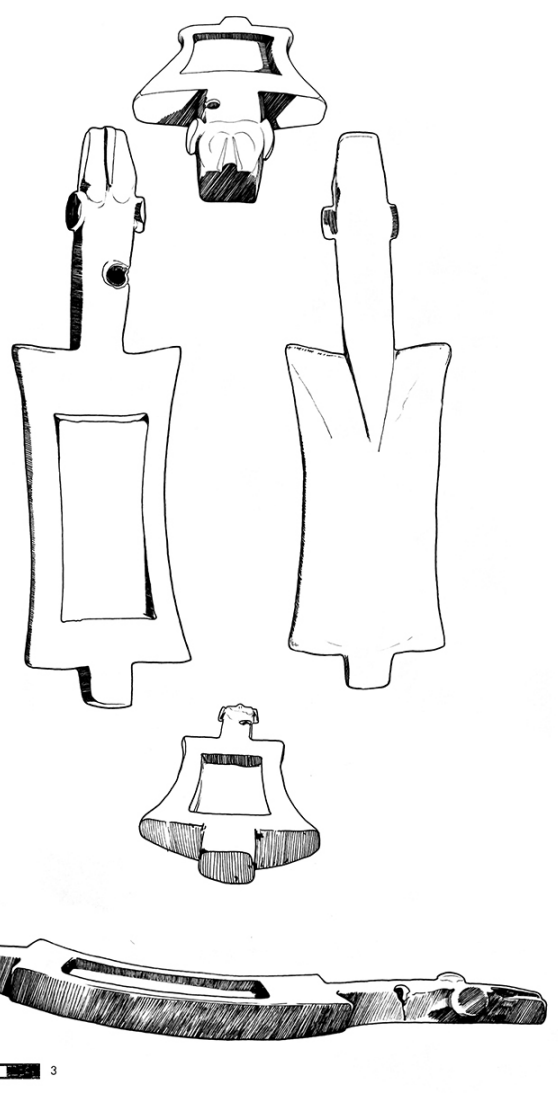

Figura 7b. Dibujo de la tableta 9296 (Col. IIAM 317), tumba 1194 del cementerio Tchecar, en sus diferentes vistas (dibujo de Alex Olave). 

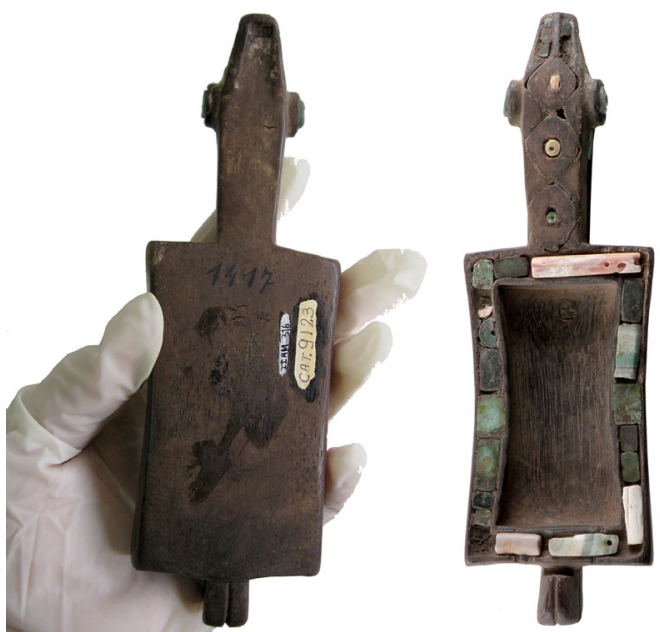

Figura 8. Tableta 9123 (Col. IIAM 316), tumba 1417 del cementerio Yaye 1, con incrustaciones cubriendo todo el borde de la pieza (fotos H. Horta).

\section{Dispersión geográfica del estilo Atacameño (Variante 1. Cabeza de Felino)}

La Figura 9 da cuenta del área de dispersión de las tabletas de este estilo, resultando evidente que provienen básicamente del salar de Atacama y de la cuenca del río Loa, con apariciones aisladas en la costa del Pacífico y en el noroeste de Argentina ${ }^{8}$ (véase Tabla 3). El núcleo duro en términos geográficos parece corresponder a lo que la literatura especializada ha dado en llamar "área atacame-

8 La investigadora argentina, M. Montenegro reúne en su Caso 1 a los ejemplares con apéndices de cabezas de felino recabados por ella en el noroeste argentino, describiéndolo como "tableta rectangular con un apéndice tallado en volumen" (2004b: 72); cita los ejemplares de Cusi Cusi, Doncellas, Casabindo y Calilegua, que son incluidos por nosotros en la Tabla 1).

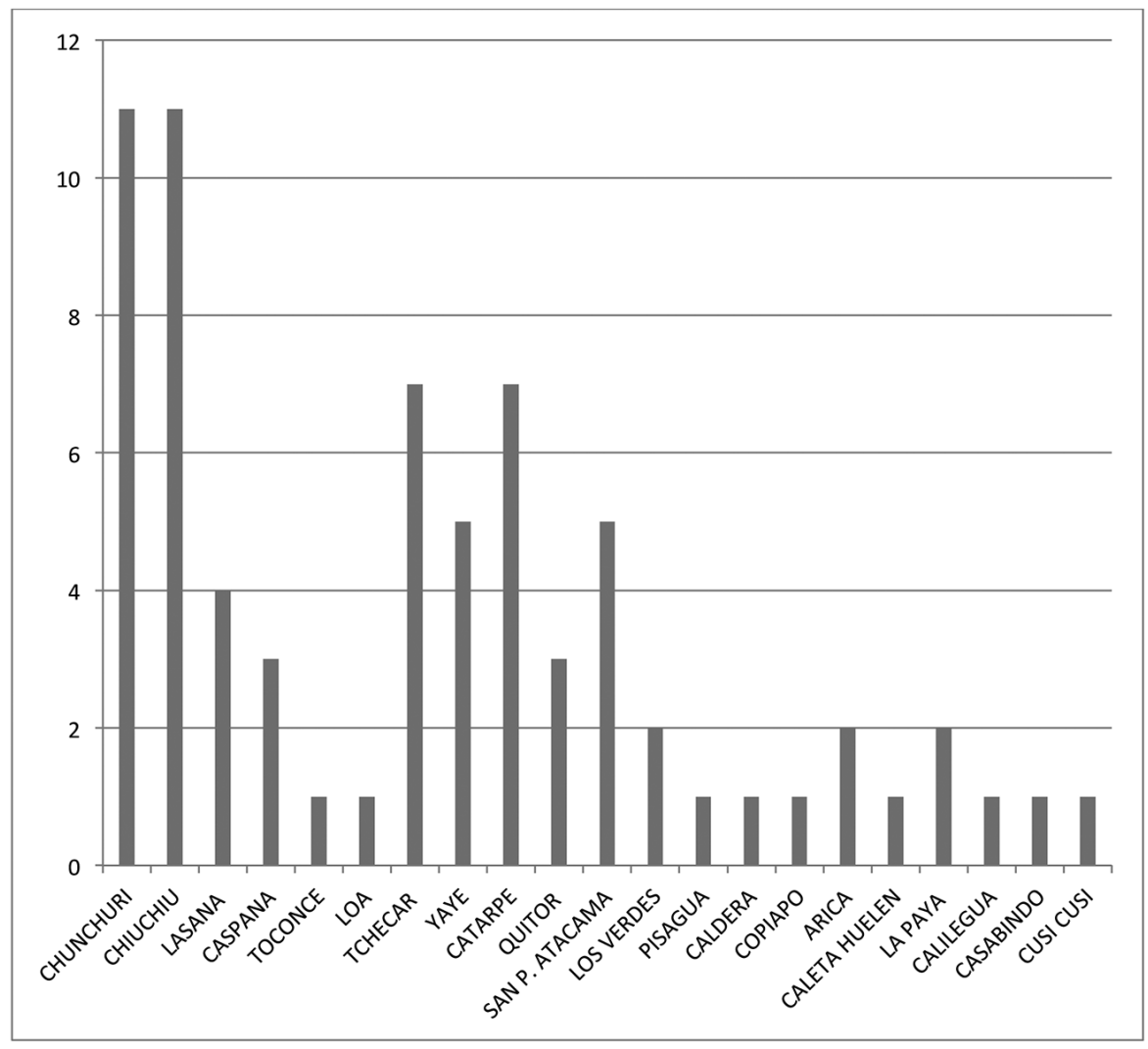

Tabla 3. Frecuencia porcentual de tabletas para inhalar alucinógenos talladas con cabeza de felino según cementerio (Norte Grande y Chico, Chile; noroeste de Argentina). 


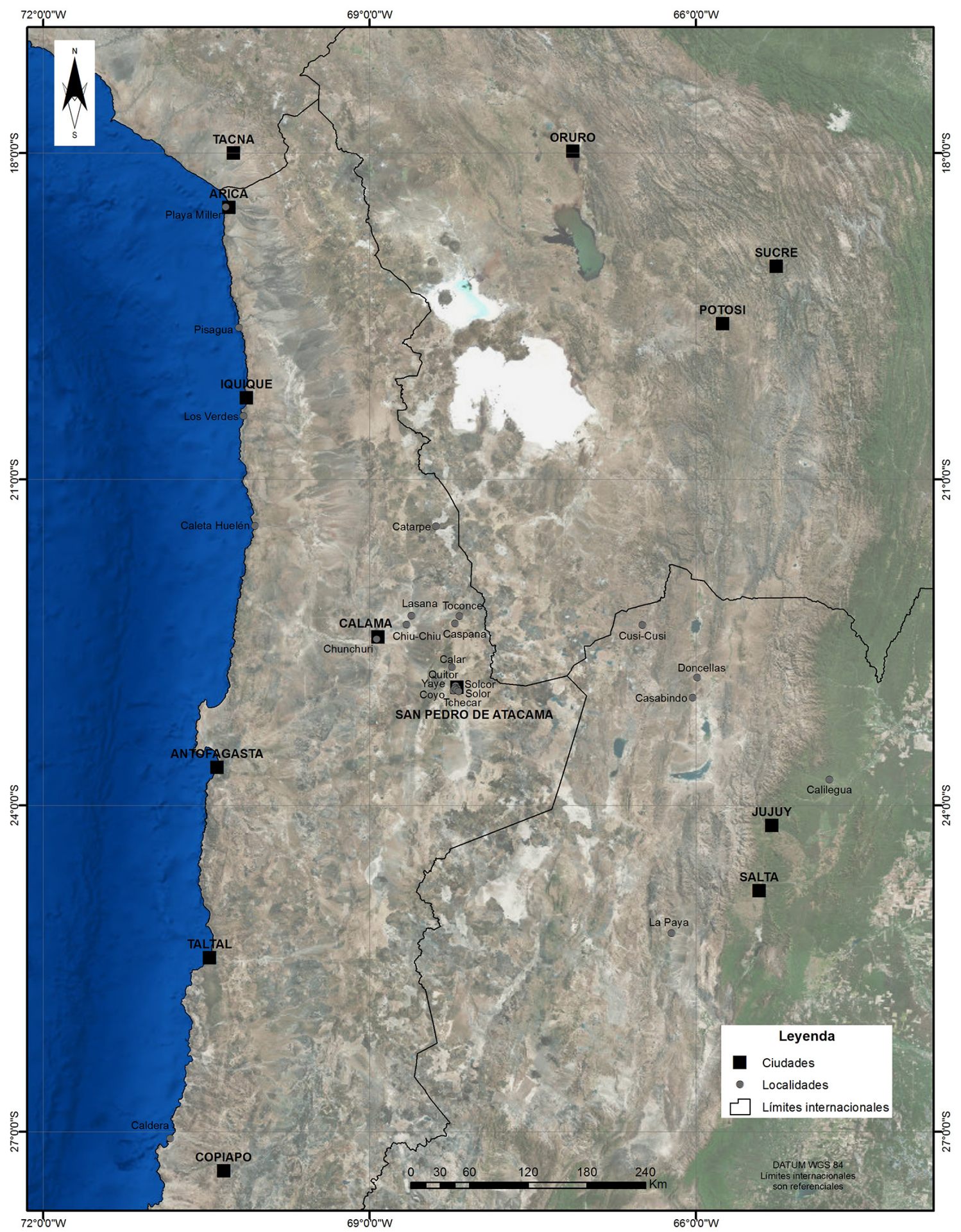

Figura 9. Mapa con la indicación de los sitios mencionados en el artículo (dibujo de Valentina Figueroa). 
ña" (Uhle 1913; Latcham 1938; Le Paige 1958, 1965, entre otros), cuyos centros en tiempos coloniales eran conocidos como "Provincia de Atacama, Alta y Baja" (Hidalgo 1978, 1984; Martínez 1998). Tomando en consideración esta área que se perfila como núcleo central de dispersión, es que proponemos denominarlo estilo Atacameño; este habría presentado tres subestilos o variantes: uno de ellos correspondería al de las tabletas con Cabeza de Felino, del cual nos ocupamos en el presente trabajo. Los otros, cuyos protagonistas son respectivamente el cóndor (Variante 2) y el quirquincho (Variante 3), serán objeto de estudios futuros.

\section{La producción minero-metalúrgica en Atacama y la aplicación de incrustaciones minerales en tabletas}

De acuerdo con observaciones realizadas previamente en relación con la numerosa colección del IIAM de implementos de la práctica inhalatoria, hemos planteado que la incrustación de minerales en el marco perimetral de las tabletas de estilo Circumpuneño (1000-1400 d.C.) parece corresponder a un rasgo propio del área del río Loa, San Pedro de Atacama y regiones vecinas, y no habría respondido a una costumbre del área nuclear de Tiawanaku, en donde probablemente sólo se incrustaban ojos y otros detalles de las figuras ubicadas en los paneles superiores de las tabletas (Horta 2012). En el estilo Circumpuneño esta costumbre se centra fundamentalmente en la aplicación de variadas piedras tales como minerales de cobre y turquesa (Thomas y Benavente 1984: 168), y excepcionalmente mullu (Spondylus princeps) en los bordes planos que enmarcan el receptáculo o cavidad central de la tableta; asimismo, se incrustan círculos de minerales de cobre o turquesa ${ }^{9}$ en las cuencas de los ojos de humanos y felinos, al igual que en las fosas nasales en el caso de representaciones de felinos (Horta 2012). En relación con la variante o subestilo Cabeza de Felino del estilo Atacameño, podemos establecer que el rol de las incrustaciones agregadas a las tabletas se vuelve protagónico.

La presencia de minerales en el marco perimetral de las tabletas corresponde a un rasgo circumpuneño inserto en una fuerte tradición cultural local vinculada a los minerales. La explotación, fabricación, uso y circulación de bienes elaborados en turquesa y en minerales de cobre formaron parte de una tradición de larga data que se encuentra perfectamente desarrollada en la región ataca- meña, al menos desde el período Formativo. Durante el período Intermedio Tardío se observa una proliferación de distritos de producción minero-metalúrgica, los que fueron a posteriori aprovechados por los inkas, quienes manteniendo la tecnología local, reorganizaron la actividad minera (Salazar 2008; Salazar et al. 2013).

Dicha tecnología minera atacameña, manifestada en tres actividades principales - lapidaria, metalurgia y pigmentaria - tiene un notable correlato arqueológico en distintos distritos minero-metalúrgicos, tales como Collahuasi, Miño, El Abra, Conchi Viejo, Chuquicamata, Cerro Verde, San Bartolo, en todos los que se reconoce una verdadera ergología minera ${ }^{10}$ (Figueroa et al. 2013; Salazar et al. 2013). Los bienes minerales de turquesa y de cobre parecen ser la ofrenda regional por excelencia, presente en sitios habitacionales, rupestres, funerarios y sobre todo, en las rutas. Las cuentas fabricadas en minerales de cobre remontan al Arcaico Tardío y están presentes hasta la época colonial (Rees 1999; Carrión 2015)ㄹ. El estudio de los caminos ha permitido poner en evidencia la relación entre las ofrendas caravaneras, los ritos y la presencia de minerales de cobre ofrendados (Pimentel 2013).

Por su parte, la producción de pigmentos verdes y azules a partir de minerales de cobre parece ser una tradición característica de Atacama y Tarapacá para tiempos tardíos, en forma coincidente con la presencia de importantes fuentes de aprovisionamiento (Sepúlveda et al. 2013). Esta riqueza y variabilidad mineral de las regiones antedichas fue desde muy temprano advertida por la empresa colonial: "Hay en este valle de Atacama y contorno de él lápiz

9 Aquí hacemos la diferencia entre minerales de cobre y turquesa, puesto que la turquesa no es un mineral de cobre, sino corresponde a un fosfato de aluminio.

10 La ergología minera corresponde a aquellos artefactos que se relacionan con el trabajo minero cotidiano, tales como martillos de piedra enmangados - mediante ligaduras de cuero y fibra de camélido - a mangos de madera, cabezales de martillos líticos, palas líticas y de madera, cestería y capachos de cuero (Figueroa et al. 2013).

11 Carrión pone énfasis en la relevancia de las cuentas de turquesa en el reforzamiento de la identidad local de los oasis de San Pedro de Atacama durante el período Medio (Carrión 2015). 
azul y jaspe de colores diferentes y negros y amarillos, turquesas finas y granates y otras diferencias de piedras de poco valory mucho, y así mismo en Tarapacá hay algunas cosas de éstas y alumbre muy rico" (Lozano Machuca 1992 [1581]).

La tecnología minera atacameña denota una alta ritualidad regional vinculada a los minerales. Se puede plantear que habría existido una ontología mineral en la cual hubo jerarquías y diferentes sacralidades para cada tipo de mineral. En el contexto de las minas de Carabaya y Chuquiabo, Berthelot (1978: 952) hace la distinción entre dos categorías de minas en función de sus beneficiarios: las minas del Inka y las minas de las comunidades locales. Esta diferencia en el control de la producción se basaba en la naturaleza geológica de los minerales: "Las minas de los grupos altiplánicos gozaban de una sacralidad menor a las minas del Inka, puesto que sus mamas (o sea las piedras sagradas consideradas los prototipos germinativos del mineral) eran de tamaño menor" (Bouysse-Cassagne 2008: 308). En otras palabras, el origen o la forma de un mineral era un principio que determinaba cierta jerarquía en relación a otros minerales.

En Atacama, dicha jerarquía debió existir y ciertos minerales con algún origen, forma o color particular habrían sido más deseados que otros. Por cierto, fue bajo su estado mineral - en diferentes tonos de color verde y azul y con forma de nódulos, polvo o cuentas de collar - que los minerales de cobre atacameños fueron ofrendados y circularon incluso más allá del área Circumpuneña. Alonso Barba señala, aludiendo a la gran distancia y prestigio asociados al tráfico de minerales de color verde:

"Turquesas muy finas en Atacama, una vi yo en los Lipes, tan grande como un real de a dos, es gala muy estimada entre los indios de esta provincia traer sartas de pedrezuelas de este género, menudas, y curiosamente labradas, traénlas los varones mas gruesas a los cuellos, como gargantillas. Haylas también de piedras verdes, y las unas y las otras es la cosa que mas apetecen los Chiriguanes de guerra, y el mas estimado rescate que se llevan" (Barba 1967 (1640): 27 en Platt et al. 2006: 152).

Por lo mismo, y a partir de los antecedentes mineros locales, es de primera importancia contextualizar la descripción de la ceremonia oficiada en Caspana, en la cual ofrecían "piedras de varios colores de pedernales y polvos de colores y davanle adorassion en Vn alto serro que mira al de
Potossí". Caspana se sitúa próxima al distrito minero de Cerro Verde, "posiblemente el centro provincial más importante construido por los incas en la cuenca del río Loa" (Salazar et al. 2013: 87). El sitio de Cerro Verde se conforma por espacios públicos (plazas y kanchas), un ushnu situado en un promontorio que domina el sector, un campamento minero, piques y desmontes mineros y su waka correspondiente (qaqa) (Salazar et al. 2013: 99). Tanto en el sector del campamento minero como en el área de explotación de la mina, el suelo está cubierto por la presencia de minerales de cobre de diversos tonos de azules y verdes. En las cercanías a Cerro Verde, en el cementerio de Los Abuelos de Caspana, se han encontrado formando parte del ajuar funerario bolsitas de cuero, cuyo contenido corresponde a un polvo muy fino de color verde fabricado a partir de la molienda de minerales de cobre (Figueroa 2012). El estudio del polvo mineral de color verde de una de ellas ha indicado que se utilizó atacamita $\left(\mathrm{CuCl}_{2} .3 \mathrm{Cu}\right.$ $\left.(\mathrm{OH})_{2}\right)$ - un hidroxicloruro de cobre - como mineral ofrendado (Sepúlveda et al. 2013).

\section{Dimensión cronológica del estilo Atacameño (Variante 1. Cabeza de Felino)}

Tal como ya se mencionó, investigaciones previas en torno a la definición de los diversos estilos que la parafernalia alucinógena presenta en el área Circumpuneña (desde la costa del Pacífico hasta el noroeste de Argentina), permiten actualmente proponer la existencia de una secuencia estilística y cronológica para la práctica inhalatoria (Horta 2012 y 2014). Esta se habría iniciado con el arribo de la influencia cultural y religiosa de Tiawanaku al área, y se ve plasmada en tabletas trapezoidales con iconografía incisa y/o tallados volumétricos, cuyos referentes se encuentran tanto en la litoescultura, como en la cerámica y los textiles conocidos para el altiplano boliviano, durante el período Medio (400-1000 d.C.). Al mismo tiempo que la práctica inhalatoria es adoptada por los atacameños, éstos desarrollan sus propias obras talladas en madera, de acuerdo a cánones estéticos propios que los distancian del estilo Tiawanaku (Núñez 1963; Thomas y Benavente 1984; Torres 1986; Llagostera et al. 1988; Llagostera 1995, 2001; Horta 2014).

Tras el derrumbe del Estado altiplánico, arriban nuevas influencias a Atacama y aparece un estilo que traspasará fronteras: el Circumpuneño (Horta 2012); éste unifica- 
rá en una misma práctica religiosa a un vasto territorio, cuyos testimonios arqueológicos han sido encontrados desde Arica hasta Taltal por la costa, y al interior, hasta el noroeste de Argentina, o la zona Lípez. ${ }^{12} \mathrm{Al}$ parecer, el estilo Circumpuneño tendrá vigencia hasta bien entrado el período Tardío (1000-1500 d. C.), y paralelamente con él se desarrollará uno más circunscrito al área atacameña propiamente tal: el estilo Atacameño que estamos definiendo en esta oportunidad en relación con el documento de Domingo Suero Leiton de Rivera. De esta manera, la variante Cabeza de Felino que analizamos aquí, corresponde a una manifestación estilísticamente tardía de la parafernalia conocida en la actualidad, cuya cuantía es de más de mil ejemplares de tabletas. ${ }^{13}$

Respecto a una ubicación cronológica más precisa para el estilo Atacameño, Montenegro menciona el fechado realizado en materiales conexos con una tableta de Jujuy, noroeste de Argentina (Montenegro 2004a); se trata del sitio Arroyo La Matanza-Cusi Cusi, de donde se obtuvo la fecha no calibrada de 1384 d.C. para una muestra ósea extraída del cuerpo del individuo I de Cusi Cusi, cuyo ajuar funerario incluía una tableta con cabeza de felino del estilo que aquí estamos definiendo. Por su parte, Krapovickas señaló en su momento - respecto del motivo de este tipo de tableta - que éste podía adjudicarse al período Tardío (Krapovickas 1958-59).

De San Pedro de Atacama mismo, contamos con el fechado $\mathrm{C}^{14}$ de 1050 d.C. para el contexto de la tumba de elite 3236-37 de Quitor 9, compuesto - entre otros artefactos de muy buena manufactura, tanto locales como exógenos - por dos tabletas: una con cabeza de felino (hoy ausente, aunque el dibujo de las Notas Le Paige referidas a esta tumba da cuenta que fue hallada y que existió un tiempo en la colección; véase foto de la pieza en Tarragó 1989: 44), y una tableta con "mujer heráldica" (sensu Torres 1987a: Plate 147). La cerámica presente en el entierro es de estilo Dupont y Huruquilla. Con estos datos se confirma para el estilo Atacameño un desenvolvimiento a través del período Intermedio Tardío y Tardío, y una muy probable vigencia resemantizada en tiempos coloniales (siglo XVII) de acuerdo con el documento citado.

Recientemente, un trabajo centrado en el análisis radiocarbónico de muestras de madera extraídas a ocho tabletas del complejo alucinógeno de la colección del IIAM, ha entregado información acerca de la posición cronológica de algunos de los estilos que hemos mencionado ( $\mathrm{Ri}$ chardin et al. 2015); según esto, los fechados obtenidos refuerzan la contemporaneidad planteada para los estilos Tiawanaku y San Pedro, así como la posición post-Tiawanaku para el estilo Circumpuneño. Desgraciadamente, no se incluyó en el análisis una tableta de estilo Atacameño, lo cual podría entregar mayor claridad respecto de su ubicación en la secuencia; no obstante, diversas asociaciones contextuales indican que tabletas de este estilo son, efectivamente, las últimas manifestaciones de la práctica inhalatoria en Atacama y zonas adyacentes. Por lo mismo, no parece arriesgado suponer que una tableta con cabeza de felino, conservada como reliquia por los chamanes o "ministros de la idolatría", hubiese podido ser utilizada en una ceremonia de ofrenda casi dos siglos más tarde..$^{14}$

12 Recientemente, en el curso de excavaciones en la Cueva del Chileno, entre los salares de Uyuni y Atacama, en tierras altas de Lípez (Bolivia), han sido encontrados por primera vez elementos de la parafernalia alucinógena, los cuales corresponden según nuestra definición estilística al estilo Circumpuneño (Albarracín-Jordán et al. 2014).

13 En este cálculo consideramos las más de 600 tabletas de la colección IAA, así como otras pertenecientes a diversos museos chilenos y extranjeros. Entre algunos de estos últimos, fue posible observar en forma directa tabletas con cabezas de felinos (Museo Arqueológico Provincial de Jujuy; Museo Etnográfico Juan Bautista Ambrosetti, Buenos Aires; Musée d'anthropologie préhistorique, Mónaco), y en otros, sólo a través de sus catálogos en línea o de ejemplares ya publicados (Museo de América, Madrid; British Museum, Londres; Museo Nacional de Antropología, Madrid; American Museum of Natural History y Museum of The American Indian, Nueva York; Museo Etnográfico de Bélgica).

14 Esta connotación de "reliquia" otorgada a tabletas se ha observado en el caso de tabletas Tiawanaku con huellas de reutilización. Existe el registro de dos casos, en que frente al desgaste por uso o por fractura del panel superior, se procedió en tiempos prehispánicos a lijarlo y rebajarlo, sin importar que la figura tallada quedase incompleta (tableta 9076 de la tumba 2509 de Quitor 6 y tableta 9075 de la tumba 2351 de Catarpe 5, con iconografía de El Sacrificador, pero en ambos casos el sector de la cabeza no se conservó; véase Richardin et al. 2015: Fig. 2.1 y 2.5). 


\section{Tabletas usadas como yesqueros}

Refuerza la idea de la sobrevivencia de este estilo hasta tiempos coloniales tempranos, un hecho especial que ha sido registrado en 16 tabletas de estilo aún no definido, y que aparentemente tuvieron vigencia durante el período Tardío. ${ }^{15}$ En ellas se han detectado huellas de quema en forma de orificios tubulares, situación no registrada hasta aquí en relación con la parafernalia propia de los estilos Tiawanaku o San Pedro, del período Medio, o con el Circumpuneño, del Intermedio Tardío. Entre las tabletas con huellas de quema contamos con una que pertenece a la variante esquemática del estilo Atacameño; ésta - además de presentar "cola"- exhibe en el cuello del felino un orificio con las huellas de la fricción ejercida sobre la madera, lo cual originó un orificio tubular bastante regular en el borde mismo; se trata de la tableta 9296 de Tchecar (véase Figuras $7 \mathrm{a}$ y b).

Al interior de los orificios de varias de estas tabletas, se aprecian huellas de hollín, sedimentados en la madera, en todo similar a las huellas de quema características de los yesqueros. Conviene destacar el hecho, de que la mayo-

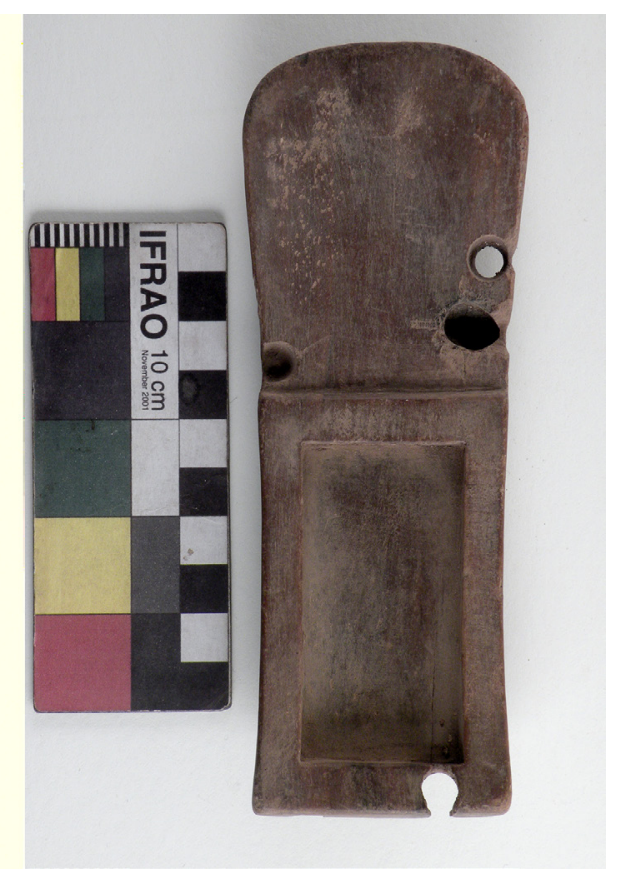

Figura 10. Tableta lisa 8914 , tumba 2553 del cementerio Catarpe 5; se aprecian orificios con huellas de quema y otros puntos taladrados (registro fotográfico Col. IIAM 165). ría de los orificios fueron excavados en el panel superior de la tableta, tanto por el anverso como por el reverso, próximos al borde del panel superior. En varios casos, la madera ha sido taladrada completamente, de lado a lado, producto de lo cual aparecen círculos vacíos en los laterales (Figura 10). Este último detalle hace descartar la posibilidad alternativa de que dichos orificios hubiesen sido pensados para alojar incrustaciones: los desgastes para insertar cuentas o bloques minerales no tienen formas regulares y nunca son tubulares; asimismo, las incrustaciones no se disponen en los bordes de los paneles superiores, sino formando parte de las figuras talladas, o como adornos del reborde exterior de la cavidad de la tableta.

A primera vista resulta inexplicable la razón por la cual hubiese sido necesario utilizar tabletas como yesqueros. Creemos que esta situación refuerza nuestra propuesta acerca de que el documento de 1674 describe precisamente a una tableta de estilo Atacameño, en su variante esquemática, la cual no estaba siendo usada para depositar en ella los polvos alucinógenos que se habrían de inhalar en la ceremonia, sino simplemente como bandeja de polvos y piedras minerales, y en el primer caso, especialmente, frutos de la primera cosecha que serían entregados como ofrendas. Como es ampliamente conocido, en los Andes las ofrendas prehispánicas eran incineradas, práctica que también podríamos suponer para Ata$\mathrm{cama}^{16}$. De este modo, la chispa necesaria para generar la combustión, y a su vez, la incineración de los elementos ofrendados, habría sido lograda mediante el uso de la tableta como yesquero sagrado.

15 Se trata de las siguientes tabletas: 9100 de Catarpe 2, tumba 2299; 8953 de Catarpe 5, tumba 2345; 8955 de Catarpe 5 tumba 2381; 8950 de Catarpe, tumba 2350; 8914 de Catarpe 5, tumba 2353; 8894 de Catarpe 5, tumba 2387; 9089 de Coyo O., tumba 4027-4030; 9069 de Quitor 1, tumba 3458; 8933 de Quitor 6, tumba 2627-2631; 8948 de Quitor 6, tumba 3573-3576; 9038 de Quitor 6, tumba 2627-2631; 8924 Sin Ref./Catarpe, sin tumba; 9064 de Solcor Plaza, tumba 613; 9296 de Tchecar Túmulo Sur, tumba 1194; 8929 Sin Ref., tumba 4434-4435 y tableta Sin $/ N^{\circ}$ de Toconce, tumba 84.

16 Ver entre otras citas de cronistas las siguientes: Anónima: 155; Arriaga: 210-211; Betanzos: 51, 67, 72; Molina: 76; Santillán 112. 
De esta manera, la explicación más plausible está relacionada precisamente con el cambio de función que debieron sufrir estos implementos en tiempos post-Conquista: de contenedor de los polvos del cebil y otros aún no identificados que eran inhalados, a contenedor de ofrendas sólidas que habrían sido incineradas. ${ }^{17}$

\section{* Conclusiones}

En relación a los objetos descritos como "ídolos" en el documento notarial del extirpador de idolatrías Domingo Suero Leiton de Rivera, el primero del pueblo de Lasana de "forma de un platillo quadrado de madera de algarobo con dos figuras de ximios en cuio hueco le echavan comidas las primeras que los yndios de dicho pueblo cogian en sus sementeras a quien ofresian adorassion"; y el segundo ídolo, en el cual nos hemos concentrado en este artículo: "en el pueblo de Caspana a manera de lagarto de la mesma madera con la voca avierta al qual le ofresian piedras de varios colores de pedernales y polvos de colores y davanle adorassion", no cabe duda que tal descripción coincide con los restos materiales de las tabletas para inhalar que se usaron en el área Circumpuneña, durante el período prehispánico tardío. De hecho, en el registro arqueológico conocido para esta área, no existe otro artefacto de madera con características de "platillo cuadrado", sobre el cual se pudiese suponer que pudo haber sido el implemento utilizado en el curso de las ceremonias relatadas.

Sin embargo, donde los extirpadores vieron un lagarto, nosotros observamos - apoyándonos en el conocimiento de la iconografía local - una cabeza de felino, animal por lo demás de honda tradición y de indiscutible protagonismo en los sistemas iconográficos andinos, situación que no es comparable con el rol jugado por el lagarto. Por otra parte, dentro del ámbito del lenguaje visual atacameño del período preincaico, y más específicamente, en la iconografía de la parafernalia alucinógena, no se ha podido observar la representación del lagarto o lagartija; el único caso conocido corresponde a una pieza de iconografía foránea que presenta una bella y naturalista lagartija (tubo para inhalar $\mathrm{N}^{\circ} 8439$ de estilo Tiawanaku de la tumba 112 del cementerio Solcor 3; Llagostera et al. 1988: Fig. 13) ${ }^{18}$. De acuerdo con el análisis desarrollado en el presente trabajo, ha sido posible observar en las tabletas de estilo Atacameño el proceso de abstracción que experimenta la figura inicialmente naturalista del felino; ésta alcanza formas tan extremadamente estilizadas que su reconocimiento como felino se torna difícil, y termina siendo cercana a la conformación de la cabeza de un lagarto. En este sentido, la identificación que hace el relator español de la figura de la tableta con un lagarto es perfectamente comprensible.

A través del documento tratado en este artículo, vemos en estos cultos tanto la resemantización de un objeto sagrado prehispánico, vinculado a los ancestros, como la permanencia de ritos que perseguían asegurar la reproducción social y la fertilidad de las cosechas y de las minas. El tercer ídolo refuerza las mismas ideas, pero asociado a los cultos vinculados con la limpia de canales donde se destaca la doble función de los caciques, autoridades investidas por las autoridades españolas cristianas, pero a la vez encabezando el culto a los ancestros y a la fertilidad, del cual han sobrevivido en parte los ritos asociados a la limpia colectiva de los canales (Mostny 1954, 1968/69; Castro y Varela 1994; Lagos et al. 1988, entre otros).

Estos documentos coloniales nos hablan de continuidades y cambios, que se ven reforzados por el culto a Sotar Condi, descubierto por Francisco Otal, primer extirpador de Atacama; la vestimenta de este ídolo (vestido de cumbi y tocado con un pillu) nos remite a atuendos propios del período incaico, pero asumido como un culto regional o de "estas provincias".

En relación al acto litúrgico de quema del ídolo Sotar Condi, un testigo eclesiástico, el padre Ignacio de Cepeda y Toledo, recuerda que en la prédica de Otal, éste les habría dicho a los campesinos indígenas presentes: "Que los demonios...por medio de los ydolos les desia que si no los adoraban no tendrían hijos ni fruto en sus cosechas y otros engaños semejantes" (ABNB, EC 1650, No 17. Información de los

17 Entre los elementos característicamente ofrendados en Atacama colonial, figuran: las plumas de flamenco, "cabezas de leones" (posiblemente, capuchones fabricados de pellejo de felino; véase Horta 2014), chicha, quilapana (chicha de chañar; Martínez 1998), cuyes, camélidos, hojas de coca, “yerba cata" (vegetal de origen desconocido) (Probanza de méritos de Francisco de Otal, 1642 , f. 11v, 12r).

18 Esta particularidad de la iconografía atacameña contrasta con la iconografía de Valles Occidentales, en donde el lagarto goza de una importante frecuencia, tanto en textiles como en queros de madera y cerámica (Horta 2005 y 2013). 
servicios del Licenciado Francisco de Otal, Racionero de la Catedral de La Plata). De acuerdo a este testimonio, Otal conocía el significado que la población atacama asignaba a los poderes inmanentes de las huacas en relación con la reproducción social y la fertilidad necesaria en la economía campesina. Por otra parte se trataba de divinidades que eran a la vez temidas y veneradas.

$\mathrm{Al}$ asistir a estas ceremonias apreciamos que antes del proceso extirpador ya se había producido un cambio en el uso de las tabletas, pues al romperse los circuitos ideológicos y de aprovisionamiento de las sustancias alucinógenas, el culto nativo se recrea distinto, pero sobre las antiguas matrices del significado y relevancia del culto a las huacas. Sin duda también asociado al culto de los ancestros que permeaba la religión local.

Las piedras y polvos minerales de colores, agradables a los ojos de las huacas, seguían siendo usadas en los sacrificios y nos plantean cuales eran los circuitos de aprovisionamiento que deben ser investigados para esta época. La ofrenda de minerales de colores, en un distrito minero cuprífero como lo fue Caspana-Cerro Verde, debe ser comprendida a partir de la ritualidad regional vinculada a huacas mineras y a sus minerales.

Así como el documento describe la permanencia de ritos vinculados a la fertilidad de las cosechas, se observa un posible rito asociado a la fertilidad minera. Cabe además señalar las analogías percibidas en el sistema de representaciones andinas entre el mundo vegetal y el mundo mineral, cuyas convergencias se manifiestan en un vocabulario común (Bouysse-Cassagne 2004: 65).

A su vez, las tabletas nos remiten a una tradición inhalatoria de larga duración, asociada a cultos chamánicos que sufrieron cambios en el espacio geográfico y en el tiempo. Constituyeron instrumentos de dicha práctica, pero en ella también se encuentran presentes influencias políticas, religiosas y artísticas que simbolizan contextos culturales. Las tabletas funcionaron como instrumentos de comunicación con los dioses; también nos transmiten por medio de sus formas el culto a aquellos y los sacrificios que se les rendían.

Agradecimientos Este trabajo ha sido posible gracias al financiamiento otorgado por la Vicerrectoría de Investigación y Desarrollo Tecnológico de la Universidad
Católica del Norte, a través del proyecto Pro-Fondecyt 10301401 del año 2014. Asimismo, debemos agradecer al Proyecto Fondecyt 11130651, titulado "Tecnología y organización de la producción de cobre en el distrito Collahuasi, altiplano sur de Tarapacá", y al Proyecto Fondecyt $\mathrm{N}^{\circ}$ 1130667, titulado "Historia de los pueblos andinos de Arica, Tarapacá y Atacama: dinámicas imperiales, agencias indígenas y redes andinas de sociabilidad colonial". Aprovechamos la ocasión también para agradecer a Constantino Torres y a Emily Stovel el obsequio de fotografías de tabletas depositadas en colecciones extranjeras. Asimismo, a Ana Igareta y Verónica Lema por su enorme amabilidad en el Museo de La Plata, al igual que a Jorge Morales, Sebastián Peralta y Dina Piozzi del Museo Arqueológico Provincial de Jujuy. A Jannice Rojas de la Corporación Cultural de Calama por proporcionarnos información que le requerimos en su momento, y al coleccionista privado Patricio Chadwick por permitirnos el acceso a su hermosa colección; al colega Sönke Hartz del Stiftung SchleswigHolsteinische Landesmuseen por la cálida hospitalidad que nos brindó durante nuestra visita a Schloss Gottorf, Alemania y el acceso irrestricto al material atacameño de la colección Otto Aichel. Tampoco podemos olvidar agradecer a la colega Susan Kuzminsky por la revisión de la traducción del resumen y a Saúl Cervantes, por su ayuda permanente en las búsquedas bibliográficas.

\section{Abreviaturas}

ABNB Archivo y Biblioteca Nacional Bolivia, Sucre

AGI Archivo General de Indias, Sevilla

AMNH American Museum of Natural History, Nueva York

IIAM Instituto de Investigaciones Arqueológicas y Museo R.P. Gustavo Le Paige

S.J., San Pedro de Atacama, Universidad Católica del Norte

MA Museo de América, Madrid

MAI Museum of The American Indian, Nueva York

MNA Museo Nacional de Antropología, Madrid

MCHAP Museo Chileno de Arte Precolombino, Santiago

MASMA Museo Arqueológico San Miguel de Azapa, Arica

MNHN Museo Nacional de Historia Natural, Santiago 


\author{
MHN Museo Histórico Nacional, \\ Santiago \\ MEJBA Museo Etnográfico Juan Bautista \\ Ambrosetti, Buenos Aires
}

MRA Museo Regional de Antofagasta

MRI Museo Regional de Iquique

MAP Musée d'anthropologie préhistorique, Mónaco

\section{* Referencias citadas}

\section{Documentos}

AGI, Lima, 263, N 9/1677. Lima, Informaciones de oficio y parte Domingo Suero Leiton de Rivera, presbítero, cura vicario del pueblo de San Francisco de Chio Chio, provincia de Atacama la Baja, testimonio de 1677, certificado en 1668. Publicado en Hidalgo 2011.

AGI, Charcas, Legajo 92, 105 fs. Probanza de Méritos de Francisco de Otal. Transcripción de Victoria Castro. En Idolos a Santos, Evangelización y Religión andina en los Andes del sur, V. Castro 2009. Fondo de publicaciones Americanistas, Universidad de Chile/ Centro de Investigaciones Diego Barros Arana/ DIBAM, Santiago.

ABNB, EC 1650, $N^{\circ}$ 17. Información de los servicios del Licenciado Francisco de Otal, Racionero de la Catedral de La Plata.

\section{Bibliografía}

ALBARRACÍN-JORdÁN, J., J. CAPRILES y M. Miller. 2014. Transformations in ritual practice and social interaction on the Tiwanaku periphery. Antiquity 88: 851-862.

AMBROSETTI, J. B. 1908. Exploraciones arqueológicas en la ciudad prehistórica de La Paya (valle Calchaquí, Provincia de Salta). Campañas de 1906-07. Primera y segunda parte. Revista de la Universidad de Buenos Aires, Facultad de Filosofía y Letras, Publicaciones de la Sección Antropología $\mathrm{N}_{3}$.

ANÓNIMA. 1968 [1594]. Relación de las costumbres antiguas de los naturales del Pirú. Biblioteca de Autores Españoles desde la formación del lenguaje hasta nuestros días, tomo CCIX: 151-189. Crónicas Peruanas de Interés Indígena, Edición y estudio preliminar de Francisco Esteve Barba. Atlas, Madrid.

ARRIAGA, J. P. 1968 [1621]. Extirpación de la Idolatría del Pirú. Biblioteca de Autores Españoles desde la formación del lenguaje hasta nuestros días, tomo CCIX: 191-277. Crónicas Peruanas de Interés Indígena, Edición y estudio preliminar de Francisco Esteve Barba. Atlas, Madrid.

AYALA, P., O. REYES y M. URIBE. 1999. El cementerio de Los Abuelos de Caspana: el espacio mortuorio local durante el dominio del Tawantinsuyu. Estudios Atacameños 18: 35-54.
BARÓN, A. M. 1984. Cráneos atacameños y su asociación con tabletas para alucinógenos. Simposio Culturas Atacameñas, pp.147-155, XLIV Congreso Internacional de Americanistas. Universidad del Norte, Instituto de Investigaciones Antropológicas, San Pedro de Atacama, Chile.

BERENGUER, J., V. CASTRO y O. SILVA. 1980. Reflexiones acerca de la presencia de Tiwanaku en el norte de Chile. Estudios Arqueológicos 5: 81-93.

BERENGUER, J. 1985. Evidencias de inhalación de alucinógenos en esculturas Tiwanaku. Chungara 14: 61-69.

BERENGUER, J. 1987. Consumo nasal de alucinógenos en Tiwanaku: una aproximación iconográfica. Boletín del Museo Chileno de Arte Precolombino 2: 33-53, Santiago.

BERENGUER, J. 1998. La iconografía del poder en Tiwanaku y su rol en la integración de zonas de frontera. Boletín del Museo Chileno de Arte Precolombino 7: 19-37, Santiago.

BERENGUER, J. 2001. Evidencias de inhalación de alucinógenos y chamanismo en el arte de Tiwanaku, Bolivia. Eleusis 5: 61-83.

BERTHELOT J. 1978. L'exploitation des métaux précieux au temps des Incas. Annales. Économies, Sociétés, Civilisations 33 (5-6): 948966.

BETANZOS, J. de, 1987 [1551]. Suma y narración de los Incas. Transcripción, notas y prólogo por María del Carmen Rubio. Atlas, Madrid.

BOUYSSE-CASSAGNE, T. 2004. El sol de adentro: wakas y santos en las minas de Charcas y en el Lago Titicaca (siglos XV a XVII). Boletín de Arqueología PUCP 8: 59-97.

BOUYSSE-CASSAGNE, T. 2008. Minas del sol, del Inka y de la gente. Potosí en el contexto de la minería prehispana. En Minas y Metalurgias en los Andes del Sur, entre la Época Prehispánica y el Siglo XVII. Edits. P. Cruz y J. Vacher, pp. 278-301. Instituto Francés de Estudios Andinos et Institut de Recherche pour le Développement (IRD), Sucre. 
CARRIÓN, H. 2015. "Producción e identidad. Cuentas de mineral de cobre durante el Periodo Medio en San Pedro de Atacama". Memoria para optar al título de Arqueólogo. Universidad de Chile, Santiago, Chile.

CASTRO, V. 2009. De Idolos a Santos. Evangelización y Religión Andina en los Andes del Sur. 619 págs. Fondo de Publicaciones Americanistas Universidad de Chile, Centro de Investigaciones Diego Barros Arana. Colección Antropología, Dirección de Bibliotecas, Archivos y Museos, (DIBAM), Santiago.

CASTRO, V. y V. VARELA (Eds.). 1994. Ceremonias de Tierra y Agua: ritos milenarios andinos. Editado por Fondart y Fundación Andes. Santiago.

DURÁN, E., KANGISER M. F. y N. ACEVEDO. 2000. Colección Max Uhle: expedición a Calama 1912. Publicación Ocasional $\mathrm{N}^{\circ}$ 56: 5-49, Museo Nacional de Historia Natural, Chile.

FIGUEROA, V. 2012. Métallurgie Préhispanique des Sociétés du Littoral Pacifique dans le Chili Septentrional (850 apr. J.-C.-1540 apr. J.- C.). Thèse de Doctorat, Université de Paris I Panthéon-Sorbonne.

FIGUEROA, V., D. SALAZAR, H. SALINAS, P. NÚÑEZ-REGUEIRO y G. MANRÍQUEZ. 2013. Pre-hispanic mining ergology of northern Chile: an archaeological perspective. Chungara Revista de Antropología Chilena 45: 61-81.

HIDALGO, J. 1978. Incidencias de los patrones de poblamiento en el cálculo de la población del partido de Atacama desde 1752 a 1804. Las revisitas inéditas de 1787-1792 y 1804 . Estudios Atacameños 6: 53-111. [Reproducido en Hidalgo 2004]

HIDALGO, J. 1984. Complementariedad ecológica y tributo en Atacama. 1683-1792. Estudios Atacameños 7: 422-442. [Reproducido en Hidalgo 2004]

HIDALGO, J. 2004. Historia Andina en Chile. 705 págs. Editorial Universitaria, Santiago.

HIDALGO, J. 2011. Redes eclesiásticas, procesos de extirpación de idolatrías y cultos andinos coloniales en el corregimiento de Atacama, siglos XVII-XVIII. Estudios Atacameños 42: 113-152. [Reproducido en Hidalgo 2014]

HIDALGO, J. (Ed.). 2014. Historia Andina en Chile, vol. II. Políticas imperiales, dinámicas regionales y sociedades indígenas. 575 págs. Editorial Universitaria, Santiago.

HORTA T., H. 2005. Arte Textil Prehispánico. Diseños de los tejidos de la cultura Arica (1000-1470 d. C.). Serie Colección Estudios Regionales y Locales de la Universidad Bolivariana, Santiago, Imprenta LOM. ISBN 956-8024-21-2.
HORTA T., H. 2012. El estilo Circumpuneño en el arte de la parafernalia alucinógena prehispánica (Atacama y noroeste argentino). Estudios Atacameños 43: 5-34.

HORTA, T., H. 2013. Queros de madera del Collasuyu: nuevos datos arqueológicos para definir tradiciones (siglos XIV-XVI). Estudios Atacameños 45: 95-116.

HORTA T., H. 2014. Lo propio y lo ajeno. Definición del estilo San Pedro en la parafernalia alucinógena de los oasis del salar de Atacama. Chungara, Revista de Antropología Chilena 46/4: 559-583.

HUBBE, M., OVIEDO, M. y C. TORRES-ROUFF. 2011. Estado de conservación y contextualización cronológica de la Colección Osteológica "Gustavo Le Paige". Estudios Atacameños 41: 29-44.

KRAPOVICKAS, P. 1958-59. Arqueología de la Puna argentina. Anales de Arqueología y Etnología, tomos 14-15, Universidad Nacional de Cuyo, Facultad de Filosofía y Letras, Mendoza, Argentina.

LAGOS, R., E. MENDOZA, N. AMPUERO y N. HERNÁNDEZ. 1988. La limpia de canales y acequias de Santiago de Río Grande. Chungara 21: 43-78.

LATCHAM, R. 1938. Arqueología de la región atacameña. Prensas de la Universidad de Chile, Santiago.

LAURENCICH MINELLI, L. y M. COLELLA. 2008. Collezione Precolombiana Campagner. Il Volo Sciamanico. Vol. Primo. Museo del Seminario Vescovile, Treviso, Italia.

LE PAIGE, G. 1955-1975. Notas de Campo. Material manuscrito inédito depositado en la Unidad de Colecciones y Conservación del Instituto de Investigaciones Arqueológicas y Museo R.P. Gustavo Le Paige S.J., Universidad Católica del Norte, San Pedro de Atacama.

LE PAIGE, G. 1958. Antiguas culturas atacameñas en la cordillera chilena (II Parte). Anales de la Universidad Católica de Valparaíso 4 y 5 , Santiago.

LE PAIGE, G. 1965. San Pedro de Atacama y su zona (14 temas). Anales de la Universidad del Norte $\mathrm{N}_{4}^{\circ}$, Antofagasta.

LOOSER, G. 1926. Las tabletas para tomar rapé del Museo Nacional. Revista Chilena de Historia, tomo XXX: 19-22.

LOZANO MACHUCA, J. 1992 [1581]. Carta del factor de Potosí (al virrey del Perú don Martín Enríquez) en que da cuenta de las cosas de aquella villa y de las minas de los lipes. Versión paleográfica de J. M. Casassas. Estudios Atacameños 10: 30-34. 
LLAGOSTERA, A. 1995. Art in the snuff trays of the San Pedro de Atacama (Northern Chile). En Andean Art: Visual expression and its relations to Andean Beliefs and Values. Edit. Penny Dransart, pp. 5177, Worldwide Archaeology Series, vol. 13, Inglaterra.

LLAGOSTERA, A. 1996. San Pedro de Atacama: nodo de complementariedad reticular. En Integración Surandina: Cinco siglos después. Estudios y Debates Regionales Andinos 91, Xavier Albó et al. (Eds.) Centro de Estudios Regionales Andinos Bartolomé de las Casas / Corporación Norte Grande / Taller de Estudios Andinos / Universidad Católica del Norte, Cuzco-Antofagasta.

LLAGOSTERA, A. 2001. Archaelogy of Hallucinogens in San Pedro de Atacama (North Chile). Eleusis 5: 101-121, Arqueología de los alucinógenos en la región andina, número especial. C. Torres yA. Llagostera (Eds).

LLAGOSTERA, A. 2004. Los antiguos habitantes del Salar de Atacama. Prehistoria Atacameña, Universidad Católica del Norte, Editorial Pehuén, Antofagasta, Chile.

LLAGOSTERA, A. 2006a. Contextualización e iconografía de las tabletas psicotrópicas tiwanaku de San Pedro de Atacama. Chungara $38, \mathrm{~N}^{\circ}$ : 83-111.

LLAGOSTERA, A. 2006b. San Pedro de Atacama y el sistema reticular de interacción puneña. En Esferas de Interacción Prehistóricas y Fronteras Nacionales Modernas: los Andes Sur Centrales, editado por H. Lechtman, pp. 303-328. Instituto de Estudios PeruanosIntitute of Andean Research, Lima, Perú.

LLAGOSTERA, A.; C. TORRES y M. A. COSTA. 1988. El complejo psicotrópico en Solcor-3 (San Pedro de Atacama). Estudios Atacameños 9: 61- 98.

MARSILLI, M. 2014. Hábitos Perniciosos: Religión Andina Colonial en la Diócesis de Arequipa (siglos XVI al XVIII). Dirección de Bibliotecas y Museos (DIBAM), Centro de Investigaciones Diego Barros Arana, Santiago.

MARTÍNEZ, J. L.1998. Pueblos del chañary el algarrobo. Los atacamas en el siglo XVII. DIBAM - Facultad de Filosofía y Humanidades Universidad de Chile, Santiago, 220 págs.

MOLINA, C. de, el Almagrista. 1968 [1553]. Relación de las muchas cosas acaescidas en el Perú. Biblioteca de Autores Españoles desde la formación del lenguaje hasta nuestros días, tomo CCIX: 57-95. Crónicas Peruanas de Interés Indígena, Edición y estudio preliminar de Francisco Esteve Barba. Atlas, Madrid.

MONTENEGRO, M. 2002. Complejo alucinógeno e ideología: acerca del contexto simbólico de las tabletas para inhalación de sustancias psicoactivas de la Provincia de Jujuy, Argentina. Tesis inédita de Licen- ciatura en Antropología, Facultad de Humanidades y Ciencias Sociales, Universidad Nacional de Jujuy, Argentina.

MONTENEGRO, M. 2004a. Los caminos del complejo alucinógeno: acerca de las tabletas para uso de sustancias psicoactivas del norte de Chile y noroeste argentino durante el período de Desarrollos Regionales. Tesis de Magister en Antropología, Programa de Postgrado UCN/UTA, Instituto de Investigaciones Arqueológicas y Museo R.P. Gustavo Le Paige S.J. (IIAM), Universidad Católica del Norte, Chile.

MONTENEGRO, M. 2004b. El complejo alucinógeno allende los Andes: analogías entre las tabletas para inhalación de sustancias psicoactivas del norte de Chile y del noroeste argentino. Eleusis 8: 65-83, Journal of Psychoactive Plants \& Compounds.

MOSTNY, G. 1958. Máscaras, tubos y tabletas para rapé y cabezas-trofeos entre los atacameños. Miscellanea Paul Rivet, sobretiro, México.

MOSTNY, G. 1968/69. Ideas mágico-religiosas de los “atacamas". Boletín del Museo Nacional de Historia Natural XXX: 129-143, Santiago de Chile.

MOSTNY, G., F. JELDES, R. GONZÁLEZ y F. OBERHAUSER. 1954. Peine. Un pueblo atacameño. Publicación $\mathrm{N}_{4}^{\circ}$ del Instituto de Geografía, Universidad de Chile, Santiago.

NÚÑEZ, L. 1962. “Tallas prehispánicas en madera. Contribución a la arqueología del norte de Chile". Tesis de licenciatura para optar al título profesional de profesor en Historia, Geografía y Educación Cívica. Instituto Pedagógico, Facultad Filosofía y Educación, Universidad de Chile, Santiago.

NÚÑEZ, L. 1963. Problemas en torno a la tableta de rapé. Anales de la Universidad del Norte 2: 149-168. Congreso Internacional Arqueología de San Pedro de Atacama.

NÚÑEZ, L. y V. CASTRO. 2011. iCaiatunar, Caiatunar! : pervivencia de ritos de fertilidad prehispánica en la clandestinidad del Loa (norte de Chile). Estudios Atacameños 42: 153-172.

ORELLANA, M.1963. La Cultura de San Pedro. Arqueología Chilena 3:3-43, Centro de Estudios Antropológicos, Santiago.

OYARZÚN, A. 1979 (1931). Las tabletas y los tubos para preparar la paricá en Atacama. Estudios Antropológicos y arqueológicos. Compilación, notas y bibliografía de M. Orellana R., pp. 112120. Editorial Universitaria, Santiago de Chile.

PIMENTEL, G. 2013. "Redes viales prehispánicas en el Desierto de Atacama: viajeros, movilidad et intercambio". Tesis para optar al grado de Doctor en Antropología. Universidad Católica del Norte-Universidad de Tarapacá. 
PLATT, T., T. BOUYSSE-CASSAGNE y O. HARRIS. 2006. Qaraqara-Charka. Mallku, Inka y Rey en la Provincia de Charcas (Siglos XV-XVII). Historia Antropológica de una Confederación Aymara. IFEA, Plural, University of St. Andrews, University of London, Inter American Foundation and FCBCB, La Paz.

RAMOS, G. 1992. Políticas eclesiásticas y extirpación de idolatrías: discursos y silencios en torno al Taqui Onkoy. Revista Andina 10 (1): 147-169.

REES, CH. 1999. Elaboración, distribución y consumo de cuentas de malaquita y crisocola durante el período Formativo en la vega de Turi y sus inmediaciones, subregión del río Salado, norte de Chile. En Los Tres Reinos: Prácticas de Recolección en el Cono Sur de América, Edits. C. Aschero, A. Korstanje y P. Vuoto, pp. 85-98. Instituto de Arqueología y Museo, Universidad Nacional de Tucumán, Tucumán.

RICHARDIN, P.; C. LAVIER, H. HORTA, V. FIGUEROA y N. LIRA. 2015. Radiocarbon Dating of Prehispanic Snuff Trays from San Pedro de Atacama (Chile): Updating Stylistic and Chronological Correlations. Radiocarbon. An International Journal of Cosmogenic Isotope Research 57/5: 775-784 (Universidad de Arizona), USA.

RUIZ, M. y M. E. ALBECK. 1999. Viajeros altiplánicos. Momias de Cusi-Cusi, Depto. de Santa Catalina, Provincia de Jujuy. Una revisión. IV Jornadas Nacionales de Antropología Biológica, Universidad Nacional de Jujuy, Argentina.

SALAZAR, D. 2008. La organización de la producción minera en San José del Abra durante el Período Tardío. Estudios Atacameños 36: 43-72.

SALAZAR, D., J. BERENGUER y G. VEGA. 2013. Paisajes minerometalúrgicos incaicos en Atacama y el altiplano sur de Tarapacá (Norte de Chile). Chungara Revista de Antropología Chilena 45: 83103.

SANTILLÁN, H. de, 1968 [1563]. Relación del origen, descendencia, política y gobierno de los Incas. Biblioteca de Autores Españoles desde la formación del lenguaje hasta nuestros días, tomo CCIX: 96149. Crónicas Peruanas de Interés Indígena, Edición y estudio preliminar de Francisco Esteve Barba. Atlas, Madrid.

SEPÚlVEDA, M., V. FIGUEROA y S. PAGÈS. 2013. Copper Pigment Making and its Exchange in the Atacama Desert (Northern Chile). Latin American Antiquity 24(4): 467-482.

SPROVIERI, M. 2008-2009. Alucinaciones en circulación. Una mirada a la interacción surandina tardía desde las tabletas y tubos de La Paya (valle Calchaquí, Salta). Anales de Arqueología y Etnología 63-64: 81-105.
TARRAGÓ, M. 1989. "Contribución al conocimiento arqueológico de las poblaciones de los oasis de San Pedro de Atacama en relación con los otros pueblos puneños, en especial, el sector septentrional del valle Calchaquí". Tesis para optar al título de Doctor en Historia, Especialidad Antropología. Universidad Nacional de Rosario, Facultad de Humanidades y Artes, Argentina.

THOMAS W., C. y M. A. BENAVENTE. 1984. Reflexiones metodológicas acerca de las creencias en la cultura San Pedro a través del análisis de correspondencia de las tabletas de rapé. Simposio Culturas Atacameñas, $44^{\circ}$ Congreso Internacional de Americanistas, Manchester 1982, Inglaterra. Universidad del Norte, Instituto de Investigaciones Arqueológicas R. P. Gustavo Le Paige S. J., San Pedro de Atacama.

TORRES, C. 1984a. Tabletas para alucinógenos de San Pedro de Atacama: estilo e iconografía. En Tesoros de San Pedro de Atacama. Catálogo exhibición Museo Chileno de Arte Precolombino, Santiago.

TORRES, C. 1984b. Iconografía de las tabletas para inhalar sustancias psicoactivas de la zona de San Pedro de Atacama, norte de Chile. Estudios Atacameños 7: 178-196.

TORRES, C. 1986. Tabletas para alucinógenos en Sudamérica: tipología, distribución y rutas de difusión. Boletín del Museo Chileno de Arte Precolombino 1: 37-53.

TORRES, C. 1987a. The Iconography of South American snuff trays and Related Paraphernalia. Etnologiska Studier 37, Etnografiska Museet, Göteborg.

TORRES, C. 1987b. The iconography of the Prehispanic snuff trays from San Pedro de Atacama, Northern Chile. Andean Past, vol. 1: 191-254.

TORRES, C. 1998. Psychoactive Substances in the Archaeology of Northern Chile and NW Argentina. Chungara 30: 49-63.

TORRES, C. 2001a. Iconografía Tiwanaku en la parafernalia inhalatoria. Boletín PUCP, $\mathrm{N}^{\circ} 5$ : 247-454, Huari y Tiwanaku: modelos versus evidencias. Segunda parte, P. Kaulicke y W.H. Isbell (Eds.), Departamento Humanidades, Pontificia Universidad Católica del Perú.

TORRES, C. 20olb. Shamanic Inebriants in South America Archaeology: Recent Investigations. Eleusis, New Series, vol. 5: 3-12.

TORRES, C. 2004. Imágenes legibles: la iconografía Tiwanaku como significante. Boletín del Museo Chileno de Arte Precolombino 9: 55-73. 
TORRES, C. y W. CONKLIN. 1995. Exploring the San Pedro de Atacama/Tiwanaku Relationship. En Andean Art: Visual Expression and his Relation to Andean Beliefs and Values. (Ed.) Penny Dransart, Worldwide Archaeology Series, Vol. 13, Avebury.

UHLE, M. 1913. Tabletas de Chiu Chiu. Revista Chilena de Historia y Geografía, tomo VIII, Santiago.

UHLE, M. 1915. Los tubos y tabletas para rapé de Chile. Revista Chilena de Historia y Geografía, tomo XVI, Santiago.

URIBE, M. 2002. Sobre alfarería, cementerios, fases y procesos durante la prehistoria tardía del desierto de Atacama (800-1600 DC). Estudios Atacameños 22: 7-31.

URIBE, M., L. ADÁN, C. AGÜERO. 2004. Arqueología de los períodos Intermedio Tardío y Tardío en San Pedro de Atacama y su relación con la cuenca del Río Loa. Chungara 36: 943-956.
VAÏSSE, E., F. HOYOS y A. ECHEVERRÍA y REYES. 2006 [1896]. Glosario de la lengua atacameña. Imprenta Cervantes, Santiago.

WASSÉN, H. 1965. The use of some specific kinds of South American Indian Snuff and related Paraphernalia. Etnologiska Studier 28, Etnografiska Museet, Goteborg.

WASSÉN, H. 1972. A medicine man's implements and plants in a Tiahuanaco tomb in highland Bolivia. Etnologiska Studier 32, Etnografiska Museet, Goteborg.

ZERRIES, O. 1968. Beiträge zur kulturgeschichtlichen Beziehung der Südanden zum Tropischen Waldland Südamerikas (Contribución a las relaciones histórico-culturales entre Andes Meridionales y tierras selváticas tropicales en la América del Sur). Tribus 17, Veröffentlichungen des LindenMuseums. 